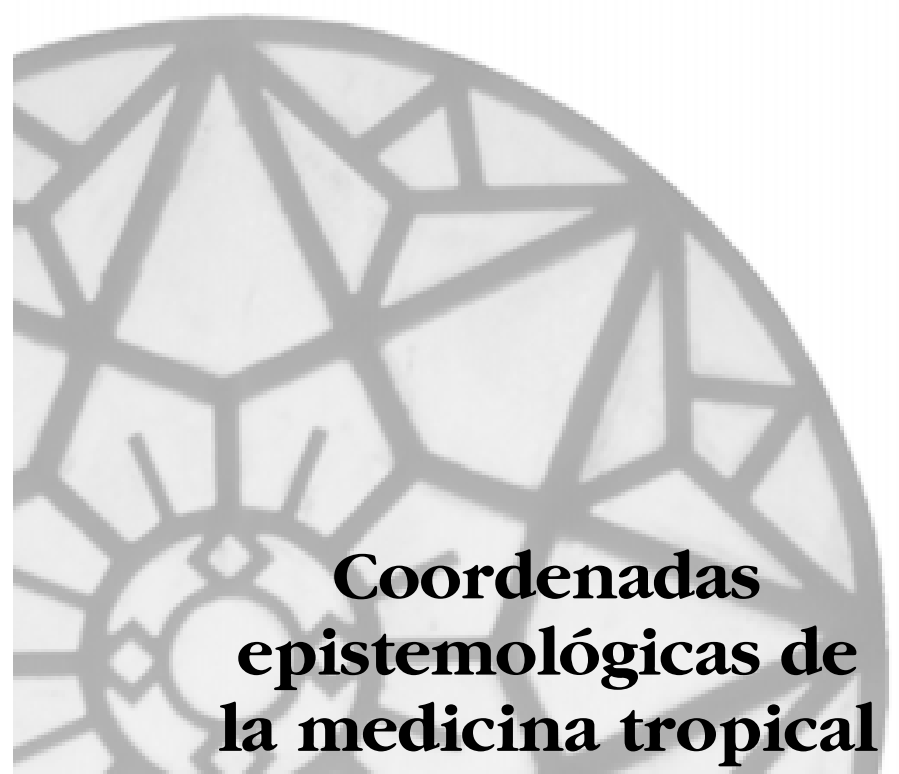

Epistemological frameworks of tropical medicine

\section{Sandra Caponi}

Professora adjunta do Departamento de Saúde Pública da Universidade Federal de Santa Catarina (UFSC) Rua Esteves Junior, 605/1414 88015-130 Florianópolis — SC Brasil sandracaponi@newsite.com.br
CAPONI, S.: 'Coordenadas epistemológicas de la medicina tropical'.

História, Ciências, Saúde-Manguinhos, vol. 10(1): 113-49, jan.-abr. 2003.

Para intentar comprender la novedad, en términos teóricos y epistemológicos,

representada por la emergencia de la medicina tropical analizamos aquí dos modelos de investigación representados por los institutos Pasteur de ultramar y The London School of Tropical Medecine. Pretendemos saber qué argumentos y conceptos entran en juego en sus discursos; de qué modo son construidos sus protocolos de investigación; en qué se diferencian y en qué se aproximan estos protocolos, conceptos y argumentos; en fin, si es posible hablar de novedad epistemológica, o de inconmensurabilidad de la medicina tropical en relación a la medicina heredera de Pasteur y a la tradición médica ocupada con las enfermedades de climas tórridos.

PALABRAS CLAVES: medicina tropical, bacteriología, historia natural, aclimatación, biogeografía.

CAPONI, S.: Epistemological frameworks of tropical medicine'.

História, Ciências, Saúde - Manguinhos, vol. 10(1): 113-49, Jan.-Apr. 2003.

In order to understand the novelty, in theoretical and epistemelogical terms, of the emergence of tropical medicine, we analyse two models of research represented by the Pasteur de Ultramar Institute and the London School of Tropical Medicine. We seek to understand which arguments and concepts come into play in their discourse; in what way they construct their protocols for research; how these protocols, concepts and arguments are similar and different; indeed, whether it is possible to speak of something new, epistemologically speaking, or of the incommensurability of tropical medicine with the medicine inherited from Pasteur and the medical tradition concerned with disease in bot climates.

KEYWORDS: tropical medicine, bacteriology, natural history, acclimation; biogeography. 


\section{Introducción}

I a preocupación médica con los trópicos, que parece haber L obsesionado a los médicos militares de las colonias europeas durante las últimas décadas del siglo XIX, traduce cierta admiración y al mismo tiempo cierto temor delante del espectáculo representado por lo desconocido, por lo diferente. Imágenes de tierras, costumbres, animales y razas exóticas se suceden en esas narraciones junto a las más variadas tentativas de dar una explicación científica a esta diversidad que representaba una clara amenaza a la salud de los colonos europeos que deseaban establecerse en ultramar.

En ese escenario sorprendente y temible, dos actores parecen ocupar un lugar central: por un lado el discurso de los geógrafos, naturalistas y médicos militares; por otro, las enfermedades que se sucedían como una condena a muerte para los blancos que deseaban instalarse en los trópicos. Nuevas enfermedades como la malaria, fiebre amarilla, enfermedad del sueño, pero también viejas conocidas como la fiebre tifoidea, la lepra o la viruela reaparecían en los trópicos con una furia mortal inexplicable. Entre todas ellas será la malaria quien ocupará el rol protagónico en esta historia, pues ella será considerada como el paradigma de la enfermedad tropical. Tal parece que el temor a estas enfermedades desconocidas podía ser comparada al miedo inspirado por mil batallas o enfrentamientos bélicos, pues la mortalidad por las llamadas "enfermedades pestilenciales" superaba inmensamente a las pérdidas de soldados en el campo de combate.

Entonces, poco a poco, en esas colonias de ultramar los médicos militares comenzaron a adquirir una función cada vez más valorada y preciosa. A ellos les era concedido el privilegio de convertir a esas regiones "palúdicas" en espacios habitables por el hombre blanco. Veremos multiplicarse diferentes hipótesis que enunciaban el privilegio de una u otra raza, que especulaban sobre la inmunidad de unos y otros o sobre las debilidades de los colonizadores para enfrentar ese mundo que se definía y se recortaba por sus diferencias de clima, de cultura, de fauna, de costumbres etc.

Es en el enfrentamiento entre esos dos mundos que se pondrán a prueba los conocimientos médicos que, hasta entonces, los centros metropolitanos habían pacientemente elaborado. Los institutos de investigación médica más conceptuados no podrán permanecer al margen de este proceso y deberán enviar sus investigadores, sus laboratorios, sus equipos y sus conocimientos a los nuevos centros que serán creados en ultramar. Este mismo proceso se reiterará en los tres centros de investigación europeos entonces más valorados: la Corona Británica enviará a Patrick Manson a China ya en 1866, el Instituto Pasteur propiciará la creación de filiales de ultramar a partir de la creación, en 1894, del Instituto de Argelia; por su parte, Alemania enviará al propio Robert Koch hacia Camerún en sucesivos viajes entre 
${ }^{1}$ Aun cuando, como lo señala Moulin (1999, p. 76), "los alemanes estuvieron, de hecho, muy presentes en África junto a los ingleses, los belgas y los franceses, siendo un zoólogo, Rudolf Leuckart, quien coordinó varias observaciones"; aun cuando con mayor movilidad que Pasteur, Robert Koch presidió diversos viajes de estudio a las colonias; $\mathrm{y}$ aun cuando reconocemos las deudas que la historia natural, específicamente la biogeografía, tienen con figuras como Humboldt $\mathrm{y}$ otros investigadores alemanes, sólo nos restringiremos aquí a analizar la medicina tropical inglesa y francesa. Siendo, sin duda esta, una limitación innegable de este estudio.
1895 y 1907 para realizar estudios sobre la malaria (Moulin, 1999, p. 76; Desowitz, 1993, p. 171). ${ }^{1}$

Para intentar comprender la novedad, en términos teóricos y epistemológicos, representada por la emergencia de la medicina tropical nos detendremos aquí a analizar las diferencias de perspectivas y de modelos teóricos que caracterizaron a dos de estos tres grandes centros de investigación. Intentaremos aproximarnos, por una parte, al modo como los institutos Pasteur de ultramar edificaron sus conocimientos relativos a las enfermedades tropicales desde su inicio, en el momento de la creación del Instituto de Argelia hasta la fundación, en 1908, por Laveran e Mesnil de la Société de Pathologie Exotique. Por otro lado, estudiaremos la emergencia de The London School of Tropical Medecine fundado por Manson en 1898.

En el caso del Instituto Pasteur, aunque la preocupación con las enfermedades tropicales que diezmaban a los colonizadores franceses en Argelia impulsó la creación de los institutos de ultramar, resta saber hasta qué punto estos centros de investigación representaron una novedad en relación al tipo de estudio que era realizado en la metrópoli por sus investigadores. Como dijimos, en el año 1894 fue creado el primer Instituto Pasteur de ultramar en Argelia, más tarde, entre 1905 y 1912, el Instituto Pasteur organizó "varias misiones de estudio sobre la enfermedad de sueño en África occidental y en África ecuatorial francesa" (Dozon, 1991, p. 272); en 1894 Roux envía a Yersin a Hong Kong para estudiar la peste; en 1897 es creado el Instituto Pasteur de Saigon; en ese periodo se sucedieron, en fin, diversos institutos Pasteur de ultramar que fueron creados en China, Indochina y África (Löwy, 1991, p. 282).

En un principio, no parecían existir muchas dudas respecto de la misión de estos institutos. Ellos deberían limitarse a "exportar" el conocimiento de los laboratorios metropolitanos, fundar laboratorios de bacteriología en las colonias, con el objetivo de reproducir los protocolos de investigación usados hasta entonces, y "formar a una nueva generación de bacteriólogos autóctonos" (ibídem, p. 283) capaces de perpetuar los modelos de investigación europeos.

Sin embargo, para poder comprender la especificidad de la medicina tropical, resulta necesario que nos interroguemos por las diferencias existentes entre los estudios clásicamente realizados en los laboratorios metropolitanos y aquellos que comenzarían a ser realizados en las colonias.

En Francia existió una figura clave que puede auxiliarnos a comprender la especificidad de la emergencia de la medicina tropical, nos referimos a Alphonse Laveran (1845-1922). Desde el año 1897, cuando ingresa al Instituto Pasteur, ganará un enorme prestigio que culminará con el premio Nóbel de 1907 por sus estudios sobre la tripanosomiasis. Gran parte de ese premio será destinada al Instituto Pasteur con un objetivo bien preciso, crear un servicio de protozoología, microbiología y entomología médica que dará lugar, en 1908, a la Société de Pathologie 
Exotique y al Bulletin de pathologie exotique que creará junto a Mesnil. Resta saber si la creación de esta sociedad representa la emergencia de un nuevo programa de investigación en relación a los estudios realizados hasta entonces en los institutos de ultramar. Al formular esta cuestión relativa a la novedad epistemológica de los trabajos de Laveran, resulta necesario que nos podamos distanciar de cualquier disputa sobre aquello que Edler (1999, p. 74) denomina la cuestión de la identidad del "padre fundador" de la medicina tropical. Por el contrario, se trata de analizar la novedad, las resistencias y la continuidad existente entre este programa de investigación y los diversos saberes que crearon las condiciones de posibilidad para su emergencia.

Es necesario destacar que ya en el año 1898 habían sido creados en Inglaterra los dos primeros centros de estudios de medicina tropical: The Liverpool School of Tropical Medicine y The London School of Higiene and Tropical Medicine. Manson había iniciado sus estudios en enfermedades tropicales veinte años antes, cuando desenvolvía sus trabajos sobre "la microfilaria de la elefantiasis y su metamorfosis en el mosquito" (Power et al., 1998, p. 54). Sin embargo, como veremos, será en los estudios de Laveran sobre la malaria donde Manson encontrará el punto de partida para la elaboración de aquello que hoy consideramos como modelo de enfermedad tropical, aquel que se define por el vínculo parásito-vector. Estos estudios posibilitarán el posterior descubrimiento de Ross del papel del mosquito en el paludismo aviario que le valdrá el premio Nóbel de 1901. El italiano Grassi especificará y profundizará estos estudios al definir el papel del Anofeles en la transmisión del paludismo para los seres humanos. Es en el interior de ese horizonte, en el que se mezclaron preocupaciones nacionalistas, raciales, imperialistas, médicas y científicas que fue definida la estrategia principal de combate a las enfermedades tropicales: el control de vectores (Fantini, 1999).

Surgen entonces dos hipótesis diferentes respecto del estatuto epistemológico de la medicina tropical. Si es verdad que a los institutos franceses de ultramar les estaba reservada la limitada tarea de aplicar, difundir y expandir los conocimientos adquiridos en la metrópoli, entonces, deberemos afirmar que la medicina tropical es solo una rama de la microbiología, la continuación, perfeccionamiento y ampliación de las estrategias de estudio de la bacteriología hacia otras enfermedades que parecían ser propias de los climas tórridos.

En este caso, a la medicina tropical le estaría asignado un estatuto epistemológico subordinado a los programas propios de la bacteriología pasteuriana. Como afirma Latour (2001, p. 226), reiterando las certezas de tantos otros historiadores franceses de la medicina, "los pasteurianos, acostumbrados a atravesar las diferentes ciencias, pueden, sin sorpresa, agregar nuevas pequeñas bestias al pulular de los microbios: todos los descubrimientos de ese periodo consisten en encontrar un camino por el cual un parásito, un insecto y un hombre pueden estar ligados". 
2 Desowitz (1993) analiza las dificultades enfrentadas por Laveran para que su descubrimiento del Plasmodium fuera reconocido por la comunidad científica en general y por el Instituto Pasteur en particular.
Pero, si esta continuidad es tan evidente no parece simple comprender cuáles fueron las razones de la resistencia de los pasteurianos delante del descubrimiento del Plasmodium por Láveran (Moulin,1999, p. 77; Desowitz, 1993, pp. 167-73). ${ }^{2}$ Este descubrimiento parecía enfrentarlos a los límites de los estudios bacteriológicos realizados hasta entonces. El Plasmodium no era una bacteria, no podía ser aislado, cultivado e inoculado en un animal; los canales de transmisión ya no eran los clásicos, agua y aire, precisaban ser postulados otros seres intermediarios.

Parece existir cierta novedad teórica de los estudios dedicados a la medicina tropical que nos lleva a afirmar que las diferencias entre estos dos programas de investigación son considerables y significativas, que, tal como lo afirma Michel Worboys (1996, p. 182), "cualquier relación entre la teoría de los gérmenes, sus prácticas y significados, y la medicina tropical de Manson necesita de una cuidadosa delimitación".

Para poder comprender las diferencias existentes entre estos programas será esencial analizar el papel que, en cada caso, jugaron los naturalistas, zoólogos y entomólogos. La especificidad de la medicina tropical no podrá ser comprendida sin analizar de qué modo los médicos militares y los naturalistas pre-pasteurianos y pre-mansonianos se enfrentaron con las poblaciones indígenas y con la diversidad de climas, razas, animales y enfermedades que allí encontraron. Quizás, sea posible afirmar que, mientras los herederos de Pasteur debieron convivir con una tradición de naturalistas y geógrafos defensores de las clásicas teorías "aclimatacionistas" que persistían desde inicios del siglo XIX, Manson y sus herederos encontraron un soporte teórico para sus investigaciones en el trabajo de los naturalistas formados en aquella misma tradición de la "biogeografía" que posibilitó la posterior emergencia del darwinismo. En esa distancia que separa a la tradición aclimatacionista de los estudios propios de la biogeografía es posible adivinar algo más que una distinción secundaria, es posible explicitar las condiciones discursivas diversas que posibilitaron que las investigaciones de los médicos militares de las colonias dirigieran sus observaciones y experiencias en una dirección y no en otra.

Percibir la especificidad de los estudios dedicados a la medicina tropical nos exige en primer lugar un esfuerzo analítico por separar las enfermedades cosmopolitas existentes en las colonias de aquellas nuevas enfermedades, muchas de ellas hasta entonces desconocidas, como la enfermedad del sueño, para poder, luego, analizar la peculiaridad de estas últimas. Veremos así que la etiología y la distribución de esas enfermedades, que requieren la intermediación de vectores para su propagación, sólo puede ser comprendida en el horizonte de esa trama de saberes que permitió vislumbrar las 
complejas relaciones existentes entre los seres vivos, así como las condiciones ecológicas que posibilitan su reproducción.

Para intentar elucidar esta trama compleja deberemos renunciar a una exposición histórica de los hechos para privilegiar un análisis epistemológico de los argumentos. A partir del momento en que nuestro interés está centrado en desvendar la novedad representada por la medicina tropical frente a los estudios clásicos de la microbiología deberemos iniciar nuestra exposición con una mirada retrospectiva que, a partir del concepto de "medicina tropical" enunciado por Manson, nos permita interrogarnos por las condiciones discursivas e institucionales que posibilitaron la emergencia de esta trama de saber.

\section{Patrick Manson: la emergencia de la "medicina tropical"}

El British Medical Bulletin (Warrell, 1998) del año 1998 está enteramente dedicado a la conmemoración de los cien años de la creación de las dos primeras escuelas de medicina tropical: The London School of Higiene and Tropical Medicine y The Liverpool School of Tropical Medicine, ambas creadas en 1898. En estos últimos años, como consecuencia de diferentes hechos significativos tales como el agravamiento del cuadro epidemiológico de diferentes enfermedades infecto-contagiosas; la emergencia de nuevas enfermedades como el Sida; la circulación cada vez más frecuente de hombres y de capital; el crecimiento de corrientes inmigratorias y las amenazas sanitarias a ellos asociadas parece haber surgido una nueva preocupación por re-definir y problematizar los conceptos de enfermedad tropical y de medicina tropical.

Así, el British Medical Bulletin inicia la presentación de este número afirmando que, "en los últimos años, la definición y la significación de la medicina tropical ha sido calurosamente debatida" (Warrell, 1998, p. 265). Veremos reiterarse esta misma afirmación en un inmenso número de textos dedicados a la medicina de las colonias, a los médicos del imperio, a las enfermedades exóticas etc. Todos ellos parecen concordar con la dificultad que existe para definir ese escurridizo espacio temático y disciplinar que es el de la medicina tropical.

Esta dificultad, que por razones que intentaremos aquí examinar, se hace más presente y explícita entre los investigadores e historiadores franceses de la ciencia, no está ausente entre los investigadores ingleses. Así, la vigésima edición de Manson's Tropical Diseases, dirigida por el presidente de la Royal Society of Tropical Medicine and Hygiene, G. C. Cook (1995), plantea una cuestión que precisa ser analizada.

Sabemos que numerosos médicos europeos trabajaron en diferentes regiones de India y África durante los siglos XVII y XVIII, creando monografías y estudios sobre las enfermedades encontradas en esas regiones a las que identificaron con "la tumba del 
hombre blanco". Sabemos también que muchas de las enfermedades que hoy llamamos tropicales se distribuyeron en los siglos XVII y XVIII en el norte de Europa y América, como puede observarse por los relatos de Shakespeare sobre la malaria; por el modo como Sydenham irá a tratar las fiebres intermitentes (nombre dado a la malaria) con quinina; por relatos de la existencia, en la Inglaterra Victoriana, de peste, tifus, cólera. Entonces, si las enfermedades tropicales parecen existir desde tiempos remotos, sin limitarse necesariamente a los climas "tórridos", la pregunta de Cook (ibídem, p. 4) parece inevitable: "¿qué es la medicina tropical?", o ¿qué es lo que configura ese espacio de saber como una disciplina autónoma?

Podríamos contentarnos con responder, como lo hacen muchos historiadores, entre ellos David Arnold (1996), que la emergencia de la medicina tropical es el efecto directo y exclusivo de una política imperialista y de las necesidades sociales y económicas que entonces se impusieron a la metrópoli en relación a sus dominios de ultramar. No existen dudas de que esta preocupación por las tierras exóticas comenzó a resultar imprescindible a partir del momento en que el "hombre blanco" decidió establecerse en esas colonias y que, sin duda, es mayor el interés por cuidar la salud de los europeos que allí desean establecerse que la preocupación (casi inexistente) con la salud de la población originaria de esas regiones.

O entonces, podríamos, simplemente, afirmar que "en cierto sentido no existe nada semejante a la medicina tropical y que, en todo caso, muchos de los escritos hipocráticos ya se referían a las enfermedades que hoy encontramos principalmente en regiones tropicales o subtropicales" (Balfour apud Cook, 1995, p. 5). En este caso limitaríamos toda novedad de la medicina tropical a una reiteración de las viejas preocupaciones climáticas de los textos hipocráticos referidos al aire y el agua. Siendo que estas preocupaciones climáticas hicieron parte de la historia de los controles higienistas de los siglos XVIII y XIX referidos a los pantanos, los cementerios, los mataderos y los espacios bajos, cerrados y cálidos que favorecían la putrefacción y, consecuentemente, la proliferación de miasmas, podríamos imaginar una línea continua entre Hipócrates, los higienistas (en su mayoría infeccionistas) y la medicina tropical. Podríamos entonces concluir que Manson, finalmente, habría articulado las preocupaciones climáticas clásicas con las teorías de los gérmenes que, en relación a las enfermedades europeas, ya habían mostrado sobradamente su eficacia.

De ser así, no parecería existir ninguna novedad epistemológica, sólo parecería existir la necesidad y la urgencia de recrear en regiones de climas tórridos las condiciones sanitarias e higiénicas necesarias para que las políticas colonialistas pudieran cumplir sus objetivos. Desde esta perspectiva estaríamos limitándonos a reiterar la misma dificultad que, según Harish Naraindas (1996, p. 28), se repite cada vez que nos interrogamos por la medicina tropical: "la génesis de esta disciplina 
nunca es cuestionada en términos de su legitimidad o ilegitimidad epistemológica y, en su lugar, la economía política es llamada para resolver el problema".

Es cierto que si nuestra preocupación fuera definir la génesis histórica de esta disciplina deberíamos referirnos a dos estudios claves dedicados a la Escuela de Medicina Tropical creada en Bahía entre los años 1860 y 1890, la llamada Escuela Tropicalista Bahiana. Nos referimos al estudio de Julian Peard (1996) y a los trabajos de Flavio Edler (2002, 1999). Sólo podemos mencionar aquí la existencia de esta escuela, cuyo análisis detenido fue realizado por esos autores. En ella se destacan los nombres de Otto Wucherer (1820-75); John Peterson (1820-82) y José Francisco Silva Lima (1826-1910), entre otros. Este último, que había realizado estudios sobre el beriberi, fue una de las referencia de Manson en Tropical Diseases quien recurrió a Silva Lima para estudiar lo que denominó de "enfermedades locales" (Manson, 1898, p. 599) indicando la relevancia de esta escuela en el contexto de los debates internacionales. Sin embargo, no es en los trabajos de Manson sobre beriberi, ni en los de Silva Lima, sino más bien en los trabajos dedicados a la filariosis primero, y a la malaria después, donde creemos que es posible encontrar cierta novedad epistemológica que debe ser analizada.

Pretendemos intentar comprender las condiciones históricas y epistemológicas que posibilitaron que hoy podamos hablar de nuevas enfermedades, de nuevas formas de transmisión y consecuentemente de nuevas formas de control y prevención específicas de las regiones de climas cálidos. Worboys dirá que en ese momento inaugural de la medicina tropical se da el pasaje de un modelo explicativo fundado en las "enfermedades en los trópicos" a otro que será el de las "enfermedades tropicales".

Aun cuando podamos afirmar, siguiendo a Edler (1999), que la Escuela Tropicalista Bahiana representa una novedad en este horizonte teórico, cuando observamos de qué modo los investigadores ingleses y franceses se ocupan de las enfermedades tropicales en sus colonias de ultramar, parece verificarse la tesis de Worboys (1996). Para él, cuando los médicos pre-mansonianos se referían a las "enfermedades de los trópicos" argumentaban que las enfermedades graves allí encontradas eran análogas a aquellas que existían en los climas templados y que, las mismas, podían ser combatidas por las estrategias clásicamente utilizadas en Europa. "Categorías como fiebres intermitentes y continuas funcionaban tanto en Madras como en Manchester, en Bermuda como en Birminghan, en Lagos como en Londres. Las diferencias eran de grado y no de tipo" (Worboys, 1996, p. 181).

Por el contrario, cuando Manson se refiere a las enfermedades tropicales se ocupa de las investigaciones referidas a un cierto tipo de enfermedades que se localizaban, principalmente, en regiones cálidas. La particularidad de las mismas estaba en que su etiología, 
su profilaxis y las medidas necesarias para combatirlas, no podían reducirse ni a una transposición de las explicaciones etiológicas conocidas ni a los cuadros nosológicos de las enfermedades europeas.

Pero, ¿̨uál es la peculiaridad de este modelo explicativo? Para intentar responder a esta cuestión analizaremos el modo como Manson conceptualiza la medicina tropical. Es verdad que, como apunta Edler (1999, p. 94), los recientes estudios dedicados a la medicina tropical se han ocupado casi exclusivamente del periodo mansoniano o posmansoniano, señalando allí una ruptura radical con el pasado y la inauguración de un nuevo saber. No pretendemos reiterar aquí, una vez más, las certezas de esta "nueva ortodoxia". Por el contrario, nos interesa interrogarnos por el estatuto epistemológico de esa medicina mansoniana que para muchos indica la fundación de un nuevo modo de observar las enfermedades en los trópicos. Pretendemos saber qué argumentos y conceptos entran en juego en ese discurso; cuáles son los saberes con los que esta medicina dialoga; de qué modo son construidos sus protocolos de investigación; en qué se diferencian y en qué se aproximan estos protocolos, conceptos y argumentos de aquellos utilizados por la microbiología pasteuriana; hasta qué punto es posible hablar de novedad epistemológica, de nuevo paradigma o de inconmensurabilidad con la tradición médica ocupada con las enfermedades de climas cálidos como sugiere Worboys (1996); en fin, comprender la novedad epistemológica de este programa de investigación, señalando, al mismo tiempo, las redes que lo vinculan con otros saberes y discursos que lo precedieron y que podemos definir como siendo su condición de posibilidad.

En la primera edición de Tropical Diseases (1898, p. xii) Manson dirá que utiliza el concepto de trópico en un sentido climático y no geográfico; dirá también que "la ciencia moderna ha visto claramente que casi todas las enfermedades son, directa o indirectamente, causadas por gérmenes". Explicará que la etiología microbiana y el clima están directamente vinculados, pues "los gérmenes son organizados, son seres vivos, y como todas las cosas vivas demandan ciertas condiciones físicas. Una de estas condiciones es cierta temperatura, otra es cierto medio y la tercera es cierta oportunidad."

Ya no es posible hablar de un retorno a las explicaciones climáticas clásicas, el clima no ocupa aquí el mismo lugar que ocupaba antiguamente en el discurso de los hipocráticos ni en las explicaciones de los infeccionistas. Si el clima puede resultar una instancia explicativa, esto se debe a su papel en la difusión de ciertas enfermedades producidas por agentes microscópicos, el papel del clima se ha transformado radicalmente por referencias a los estudios de la microbiología. Manson (ibídem, p. xiii) se pregunta: "¿En qué sentido las influencias tropicales afectan a las enfermedades, como sin duda lo hacen, y por qué ocurre que algunas enfermedades son peculiares de los climas tropicales o prevalecen especialmente en ese clima?" 
Para poder responder a esta pregunta es necesario observar la extensión del concepto de enfermedad tropical. Manson dirá que si con ese concepto quisiéramos hacer referencia a las enfermedades que ocurren exclusivamente en el trópico, un texto de 12 páginas sería suficiente para agotarlas, siendo que existen solo dos o tres enfermedades que son las únicas a las que efectivamente les cabría esta denominación, tal es el caso, por ejemplo, de la enfermedad del sueño. Si, al contrario, hacemos extensivo este concepto a todas las enfermedades que ocurren en el trópico, entonces deberíamos incluir todas las enfermedades de las que se ocupa la medicina porque la mayor parte de las enfermedades de los climas templados pueden ser encontradas también en los trópicos (ídem, ibídem, p. xi). Por esta razón Manson insiste en afirmar, a partir de 1907, que el término medicina tropical es más "conveniente" que "exacto", que "no se trata de una categoría científica, sino más bien de una categoría útil y práctica" (Worboys, 1996, p. 195).

Ese concepto, no científico pero conveniente, permite, sin embargo, reunir una serie de discursos y saberes que se articulan en torno a las enfermedades que o bien son propias y específicas de regiones cálidas (como la enfermedad del sueño) o bien tienen mayor prevalencia en estas regiones (como el cólera). Se trata, en fin, de un dominio de saber y de intervención que, desde su inicio, resulta del encuentro entre disciplinas diversas. Cook (1995, p. 4) dirá que se trata de una especialidad que tiene en su origen un suelo multidisciplinar. Por un lado responde a las conquistas de una de las áreas de mayor progreso en el siglo XIX, la salud pública (y la higiene). Al mismo tiempo se vincula con los viajes y las exploraciones científicas de los naturalistas, con la historia natural y con la teoría de la evolución y, finalmente, está directamente relacionada a la adquisición de conocimientos precisos sobre la etiología microbiana de las enfermedades infecciosas. Por otra parte, y como un elemento esencial para poder completar este verdadero rompecabezas epistemológico, "los desarrollos de la parasitología clínica siguiendo los trabajos de Laveran, Manson, Ross y otros, se sobrepusieron a este complejo telón de fondo, posibilitando la génesis de la medicina tropical".

Es el propio Manson en su Introducción a Tropical Disease quien nos permite comprender de qué modo se articularon esos saberes diversos para posibilitar la emergencia de un nuevo modelo de control de las enfermedades infecciosas que podían integrar, entre el enfermo y los agentes microbianos, una nueva serie de intermediarios vivos, los vectores, capaces de garantizar la transmisión de esas enfermedades.

El concepto de "trópico" es empleado por Manson (1898, p. xii) en un sentido meteorológico y no geográfico. Pero, sin embargo, Manson afirma que el clima le interesa solo en un sentido secundario, solo en la medida en que crea las condiciones de posibilidad de emergencia y dispersión de ciertos y determinados gérmenes (conocidos 
o aun desconocidos) causadores de las enfermedades que se reiteran en los trópicos, malaria, fiebre amarilla, enfermedad del sueño. Para él, las altas temperaturas no son causa directa sino indirecta de la existencia de esas enfermedades. Y si el clima puede provocar ciertos problemas (cansancio, fatiga, fiebre) estos cuadros no pueden ser definidos como "enfermedades" (disease) en sentido estricto, sino más bien como molestia o debilidad.

Entonces, aunque el clima pueda aparecer como un elemento indispensable para crear las condiciones de posibilidad de ocurrencia de esas enfermedades, para Manson (ibídem, p. xiii) es necesario no detenerse allí y observar no sólo las causas indirectas sino también las causas inmediatas o directas de las mismas. "En su mayor parte los gérmenes son parásitos que, para existir, requieren pasar de huésped a huésped. Si durante ese pasaje de huésped a huésped la temperatura del medio — sea agua, aire o comida — es muy alta o muy baja para los requerimientos del germen en cuestión, éste muere y deja de ser infeccioso."

De este modo, y por referencia a la escarlatina, intenta explicar por qué razón ciertas enfermedades de climas templados o fríos no reaparecen en los trópicos; y por qué razón ciertas enfermedades propias de las regiones de altas temperaturas no existen en las regiones frías o templadas, tal como es el caso del dengue. En el caso de la escarlatina, en el corto transcurso requerido para garantizar el pasaje de un hombre enfermo a otro, la temperatura tropical es fatal para el germen que reside en el aire. Por el contrario, en el caso del dengue, son las bajas temperaturas las que afectan ese pasaje, siendo que el vector más conocido de la enfermedad requiere de temperaturas elevadas para su reproducción. Hasta aquí podríamos decir que Manson reproduce las mismas preocupaciones de los pasteurianos y que reitera, una vez más, los clásicos discursos referidos a la malignidad de los climas tórridos.

Pero, para completar su argumento, Manson requiere de un cierto número de conocimientos que hasta entonces parecían ser ajenos al discurso de la microbiología y a sus demandas de aislar el microorganismo, cultivarlo en cultivo puro, inocularlo en un animal y provocar la enfermedad en cuestión. Ahora Manson (ibídem, p. xiv) postula un tercer elemento en la cadena que une al hombre (o a los animales) con los microorganismos que ya no se limita a los canales clásicos de transmisión como aire, agua, alimentos o ropas infectadas. "Muchas enfermedades requieren del servicio de un tercer animal para ser transmitidas de un individuo a otro. Si este animal pertenece a especies tropicales, entonces la enfermedad que requiere de él será necesariamente una enfermedad tropical."

Ese tercer animal que actúa como transmisor puede operar de diversos modos, puede ser simplemente un agente de transportación de microorganismos o puede actuar como un huésped intermediario. En el caso de la filariosis, estudiada por Manson, ese huésped 
intermediario resulta esencial para posibilitar la realización del completo ciclo evolutivo del parásito. La distribución de un gran número de enfermedades parasitarias depende de la distribución geográfica de estos huéspedes intermediarios vivos o vectores.

Manson insiste en la necesidad de conocer la distribución geográfica de estos artrópodos. Existían, entonces, calurosos debates en torno a la posibilidad o imposibilidad de migración de las especies; para algunos aclimatacionistas el hombre debería recrear artificialmente las condiciones para posibilitar esa migración, para otros ese fenómeno era imposible dado que a cada especie le corresponde su "lugar de destino", y para otros, tal es el caso de Darwin, la migración de las especies era un fenómeno natural que podía ocurrir en ciertas condiciones determinadas (Molina, 1999, p. 121). Hoy sabemos que esta distribución no depende exclusivamente de condiciones climáticas y que muchas especies pueden migrar y ampliar el espacio geográfico al que se las creía confinadas. Como afirma Pierre Guillet (2000, p. 8) en relación a la colonización de zonas templadas por vectores de origen tropical:

La importación de insectos de interés médico es un fenómeno corriente. Todas las investigaciones entomológicas realizadas en Europa, Estados Unidos y Japón lo demuestran. El paludismo de aeropuerto y la presencia de vectores africanos del paludismo en el aeropuerto de Roissy ilustran este fenómeno. Existen numerosos ejemplos de colonización de zonas nuevas por especies tropicales como la introducción del vector Anopheles gambiae en Egipto y Brasil. Sin embargo, se trata siempre de inmigraciones sud-sud y siempre de regiones cálidas. Hasta hoy no existe ningún ejemplo probado de colonización durable en zonas templadas por vectores de origen tropical.

Parece aceptable imaginar que, excepto que existan importantes y persistentes modificaciones climáticas, no es muy probable que las especies tropicales colonicen zonas templadas. "La biogeografía obedece a leyes bien establecidas y la repartición actual de las especies no es fruto del azar" (ídem, ibídem, p. 8). Para comprender la novedad epistemológica representada por Manson en relación a las investigaciones clásicas de la microbiología, resulta indispensable comprender que las altas temperaturas han dejado de representar esa abstracta amenaza de multiplicador de gérmenes (idea que, entonces, ya había sustituido a las teorías infeccionistas que atribuían un rol central al calor en el ciclo de la putrefacción) para pasar a ser un elemento indispensable para comprender la distribución biogeográfica de los vectores y también de los microorganismos y parásitos que causan ciertas enfermedades.

Es que, para Manson (1898, p. xv), la distribución geográfica de las enfermedades causadas por gérmenes depende no sólo de la existencia de condiciones climáticas favorables, sino también "de la ausencia de 
condiciones desfavorables". La determinación de estas condiciones constituía una enorme área de estudios entonces desconsiderada o muy poco explorada por los epidemiólogos. "Las enfermedades transmitidas por gérmenes, sus agentes transmisores y sus huéspedes intermediarios, que son organismos vivos, son en su fase extracorporal organismos necesariamente competidores, y en ese sentido susceptibles de ser amenazados por predadores. Ellos están sujetos a ser destruidos por otros organismos en la lucha por la existencia."

Tomando como modelo los estudios sobre la malaria, dirá que resulta significativo observar que esta enfermedad está ausente de varios lugares en los cuales, aparentemente, existirían todas las condiciones climáticas perfectamente favorables para desarrollarse. Se pregunta entonces por las razones por las cuales esta enfermedad no se ha propagado en estas regiones en las que ciertamente de un modo u otro puede haber sido introducida. "Quisiera sugerir que, en ciertas circunstancias, este parásito, así como los gérmenes de otras enfermedades o los organismos que posibilitan su transmisión, fueron capturados por sus enemigos naturales" (ídem, ibídem). Es así que, en nuestro conocimiento sobre enfermedades tropicales, puede resultar menos importante el rol de la temperatura que la influencia que ejerce sobre los microorganismos la inmensa variedad de fauna tropical.

En este sentido resulta innegable para Manson que los estudios de entomología, de zoología, en fin los estudios de los naturalistas no son elementos accesorios o secundarios, no son un simple complemento que viene a auxiliar a los estudios bacteriológicos realizados en el laboratorio, sino un espacio disciplinar constitutivo, como lo es la microbiología de la medicina tropical. "Es evidente que el estudiante de medicina (especialmente de medicina tropical) debe ser un naturalista antes de que pueda devenir un epidemiólogo, un patólogo, o un médico capaz de ejercer su práctica" (Manson, 1898, p. xvi). Sólo a partir del reconocimiento e identificación de la infinita variedad zoológica tropical se podía contribuir a desvendar los misterios de esas enfermedades cuyas causas permanecían desconocidas.

Pero, si observamos el índice de enfermedades estudiadas en el texto veremos que además de las enfermedades tropicales son analizadas otras enfermedades a las que Manson (ibídem) llama "cosmopolitas", por ejemplo la lepra y la peste, pues no requieren de condiciones climáticas específicas para existir. Estas enfermedades que parecían, entonces, haber desaparecido de Europa y de las regiones templadas de América, estaban confinadas a las regiones tropicales o subtropicales. Manson afirma que el avance de la civilización y las mejoras en la higiene determinaron su desaparición en ciertas regiones, mientras que en las regiones tropicales persisten condiciones sociales y sanitarias precarias que son necesarias para la propagación de las mismas. 
Lo cierto es que, en este texto, Manson (ibídem, p. xv) abordará dos grupos de enfermedades, las enfermedades estrictamente tropicales y las enfermedades llamadas cosmopolitas pero que, sin embargo, tienen mayor incidencia en las regiones tropicales. Utilizando la distinción de Worboys diríamos que habla tanto de diseases in the tropics como de tropical diseases. En relación a las primeras estimulará la continuidad de los estudios patológicos sobre enfermedades cosmopolitas que los laboratorios de ultramar realizaban desde hacía tiempo en los países tropicales. Pero, es en relación a la etiología de las enfermedades tropicales que los jóvenes médicos "ciertamente encontrarán oportunidades para realizar investigaciones originales y descubrimientos mucho más novedosos e interesantes que aquellos que son realizados en los centros de investigación europeos o americanos".

La extensión del concepto "enfermedad tropical" permanece, sin embargo, poco clara. Si por un lado Manson da inicio y estimula la creación de un nuevo modelo de estudios médicos fundado en el modelo parásito-vector que demostró ser heurísticamente progresivo y positivo para definir un amplio conjunto de enfermedades como Chagas, enfermedad de sueño, fiebre amarilla y otras que encuentran su modelo explicativo en los estudios de Ross sobre la malaria que fueron directamente estimulados por Manson; por otra parte, debemos recordar que desde el inicio Manson insiste en afirmar que las enfermedades tropicales no se reducen a las enfermedades exclusivas de los trópicos ni a aquellas transmitidas por vectores. Por enfermedad tropical, debemos entender simplemente las enfermedades infecciosas cuyo agente específico o el huésped intermediario que posibilita su transmisión exigen ciertas condiciones para propagarse que se encuentran en las regiones tropicales: cierta temperatura y cierta distribución biogeográfica de las especies.

Como puede ser observado analizando la relación de las enfermedades estudiadas en Tropical Disease, éstas no pueden reducirse al modelo parásito-vector. Encontramos enfermedades parasitarias no transmitidas por vectores cuya incidencia es mayor en los trópicos, aun cuando puedan existir también en las regiones templadas. Es posible que para poder definir cuál es la extensión que el concepto de enfermedad tropical tenía para Manson debamos preocuparnos menos por la existencia o no de vectores intermediarios que por la instauración de un nuevo espacio de visibilidad. Aquel que integra a los estudios de la microbiología, la mirada del naturalista, aquel que permite sustituir los argumentos clásicos referidos a la aclimatación por una perspectiva biogeográfica.

No sólo los huéspedes intermediarios, determinadas especie de moscas o de mosquitos, sino también los parásitos son vistos como seres vivos que compiten con otros organismos en la lucha por la vida. Entre los predadores que definen las condiciones desfavorables para la 
ocurrencia de una enfermedad se encuentran, también, las acciones sanitarias y sociales que el hombre realiza con el objetivo preciso de combatir esos agentes. Ciertos parásitos requieren que, antes de pasar al hombre, puedan realizar parte de su ciclo vital en un medio externo, como es el caso de la anquilostomiasis que requiere de altas temperaturas para desarrollarse; otros parásitos, cuyo paradigma es la malaria, requieren de un huésped intermediario donde realizan parte de su ciclo vital. Si la condición requerida para esa propagación es la alta temperatura y cierta distribución biogeográfica de vectores propia de regiones tropicales, diremos entonces que se tata de enfermedades tropicales.

Podemos intentar ahora dar una respuesta a la pregunta formulada por Anne Marie Moulin (1996b, p. 11): "Una gran anomalía parece surgir aun en los años triunfales de la medicina tropical sobre su legitimidad epistemológica, es la de la caracterización de una disciplina por su terreno de aplicación: ¿Veremos nacer una medicina polar o templada? ¿Acaso la fuerza de la medicina no está en la universalidad de sus métodos científicos y de sus postulados?" A partir de Manson, podríamos responder afirmativamente a la primera pregunta y negativamente a la segunda. Si pensamos a las enfermedades infecciosas y parasitarias, sean o no enfermedades transmitidas por vectores, desde la perspectiva de la biogeografía entonces podríamos hablar de enfermedades cosmopolitas, de enfermedades propias de regiones templadas o frías, así como hablamos de enfermedades tropicales. Manson se refiere a la especificidad de la escarlatina en el clima templado $\mathrm{y}$ al hecho de que las altas temperaturas son fatales para el germen de transmisión aérea que la produce. Por fin, digamos que la universalidad de los métodos científicos y postulados de la medicina no nos inhabilita a pensar en la especificidad biogeográfica de distribución, propagación y colonización de las enfermedades, de sus agentes causales o de los vectores que posibilitan su transmisión.

\section{De la medicina tropical a la pathologie exotique}

El texto de Manson aquí analizado parece obligarnos a cuestionar la tesis clásicamente defendida por los historiadores franceses de la ciencia en relación a la emergencia de la medicina tropical. Como ya dijimos, para muchos de ellos la medicina tropical debería ser entendida como parte de la historia de la microbiología, como efecto de la continuidad y del perfeccionamiento de los programas de investigación y de los estudios realizados por bacteriólogos y microbiólogos en la metrópoli que entonces se trasladaron a ultramar.

Así, para algunos historiadores de la ciencia, la continuidad entre microbiología y "medicina tropical" resulta evidente. Jean Pierre Dozon (1991), refiriéndose al África y a la enfermedad del sueño, y Michel y Bado (1991), en un artículo que dedican a Émile Marchoux, coincidirán 
en afirmar que la medicina tropical surge del encuentro entre bacteriología y medicina militar, entonces la guerra al microbio se aliaría con las guerras colonialistas. Por su parte, Pierre Darmon (1999, p. 451) al referirse a los vectores microbianos trazará una línea continua de descubrimientos que, por la mediación de modelos de observación y experimentación cada vez más finos, permiten aislar los microbios transportados por diferentes vectores, desde los inanimados y mecánicos a los seres vivos, desde la suciedad y los viejos trapos y libros hasta los mosquitos y las pulgas, pasando por las ratas y las moscas. "Ante la observación del aire y del agua, que son fluidos, los vectores microbianos puntuales, objetos o animales, parecen fáciles de neutralizar de una vez por todas."

Creemos, por el contrario, que la emergencia de la medicina tropical exige algo más que una precisión cada vez mayor en las investigaciones bacteriológicas, exige la asociación con otros saberes (que no pueden ser reducidos a la medicina militar) y con otros modos de construir el conocimiento que, hasta entonces, eran ajenos al tipo de investigación que preocupaba a los "cazadores de microbios". Los microbiólogos deberán asociar sus conocimientos obtenidos en el laboratorio, cada vez más cuidadosos y padronizados, a conocimientos que, hasta entonces, le eran ajenos: la entomología, la protozoología y la historia natural.

Si hacia 1898 parece instalarse en Inglaterra esta exigencia de integrar los estudios de clínicos y de laboratorio con los estudios de campo de recolección, reconocimiento y clasificación de insectos y parásitos, propios de zoólogos, helmintólogos y naturalistas, esta necesidad sólo parece hacerse explicita entre los médicos de las colonias francesas casi diez años más tarde. En el caso del Instituto Pasteur, la preocupación con las enfermedades desconocidas de los trópicos y el hecho de que era posible encontrar un campo propicio para el estudio de enfermedades cosmopolitas bien conocidas, como el cólera o la peste que abundaban en las colonias, impulsó la creación de los institutos Pasteur de ultramar y varias misiones de estudio fueron enviadas para las colonias francesas de África y Asia a partir de 1894. Los médicos coloniales podían considerarse estratégicamente situados para desvendar los secretos de la mayoría de las enfermedades. Los trópicos parecían ser la cuna de las grandes pandemias de cólera, fiebre amarilla, peste y muchas otras fiebres (Moulin, 1999, p. 74).

Sin embargo, cuando observamos cómo estaba constituido el cuerpo de médicos militares enviados a las colonias y cómo era realizada su formación, veremos que, a diferencia de los institutos mansonianos, no existía ninguna preocupación en garantizarles una formación especial o diferenciada de aquella que era obtenida por los médicos de la metrópoli. Como afirma Moulin (ibídem, p. 76): 
los médicos militares dominan la cohorte de trabajadores científicos, cadetes sin fortuna de Bretaña ... que han escogido intentar la aventura colonial. En Francia, los oficiales de salud, médicos de segunda categoría, ocupan un lugar importante. Cursos especializados son realizados en las diferentes metrópolis. En Francia es el curso libre de microbie del Instituto Pasteur, abierto en 1889, que ofrece durante largo tiempo, la sola formación práctica, y una iniciación a la investigación. Esta residencia intensiva marca a los estudiantes que quedan profundamente ligados a la casa Pasteur. Su adhesión a los gestos y a las normas de la microbiología evoca casi una nueva religión.

Esta adhesión de los médicos de las colonias a la metrópoli suponía respetar ciertos protocolos de investigación bien establecidos, fundados en la búsqueda y el aislamiento del germen específico de las enfermedades, en la preocupación por definir el mejor medio de cultivo para este germen, en la inoculación a cobayos para reproducir la enfermedad, en la búsqueda por atenuación del germen, de vacunas (a partir de 1882) y de sueros (a partir de 1894) específicos para la enfermedad. Todas las esperanzas parecían estar fundadas en las conquistas de la "revolución bacteriológica". "El espacio de las enfermedades debe modelarse al modelo microbiano, así como el mundo debía modelarse a la voluntad de los grandes imperios europeos" (ibídem, p. 75). Fue así, en el marco de esta fe optimista en una segunda revolución médica que pudieron ser realizadas importantes conquistas. El bacilo del cólera será descubierto en Egipto en 1883, un año después de la ocupación inglesa; Yersin ganará la segunda batalla en 1894, en Hong Kong, al descubrir el bacilo de la peste. El laboratorio, dirá Moulin, se convierte en un santuario.

Pero, la primera evidencia que dejará este encuentro entre la bacteriología, la medicina militar y los trópicos puede resumirse en esta afirmación de Dozon (1991, p. 271): "mientras esta conjunción se hacía más precisa ... numerosas enfermedades, particularmente la enfermedad del sueño, no se dejaban reducir a los protocolos experimentales y a las ideas pasteurianas". Muchas de esas enfermedades ofrecieron serias resistencias, tanto a la especificación del agente causal como a la producción de vacunas y sueros. En muchos casos, como la enfermedad de Chagas o la enfermedad del sueño, estas resistencias se mantienen aún hoy dada la inexistencia de vacunas. Como afirma Michel Morange (1991, p. 240): "La primera dificultad para los pasteurianos de ultramar era de orden cultural: se trataba de comprender que los métodos aplicados en Francia no eran adecuados para ser aplicados en otros países." Parece que los trópicos sólo tenían que aprender (técnicas, procedimientos, protocolos) y que ellos tenían poco o nada para enseñar.

A diferencia de Morange, quizás podamos intentar comprender estas dificultades desde una perspectiva no cultural sino 
epistemológica. Lo que los pasteurianos de ultramar no podían integrar al santuario del laboratorio era la perspectiva del naturalista, esos estudios de campo que permitieran observar la especificidad de esos seres intermediarios que garantizaban la transmisión de esas enfermedades que no podían ser transmitidas por contacto directo con el enfermo o por los canales clásicamente estudiados por los microbiólogos, aire, agua, ropa, objetos. Es que, si la llamada "revolución microbiológica" o pasteuriana parecía poder ofrecer un margen ilimitado para el conocimiento y el dominio de las enfermedades, ella imponía también ciertos límites dada la restricción de los protocolos y de las técnicas de investigación que podían ser admitidos: cultivo de bacterias e inoculación en animales.

Quizás podamos encontrar en los estudios realizados en Bombay por Paul-Louis Simond un buen ejemplo para comprender los límites del modelo de pesquisa de laboratorio. En 1897, este investigador del Instituto Pasteur levanta la sospecha y realiza experiencias tendientes a demostrar que la pulga juega un rol determinante en la transmisión de la peste. Estas experiencias consistían en depositar dos ratas, una sana y una enferma, dentro de una caja separadas por una tela que permitiera el paso de las pulgas. Aunque la rata sana resultará enferma después de la experiencia, este estudio, de hecho inconclusivo, no convencerá a ninguno de los investigadores de ese instituto ni estimulará la realización de trabajos en esa dirección aun cuando ya existieran los estudios de Manson sobre filariosis y Laveran ya hubiera enunciado su hipótesis de la transmisión de la malaria por un insecto picador. La hipótesis de Simond será rápidamente desconsiderada por la comunidad científica, llevando a ridiculizar al "magicien des puces" (Brossollet, 2000, p. 69). Sólo en 1914 se iniciarán estudios que tomarán seriamente esos trabajos que, para poder confirmarse, exigían precisiones entomológicas que definieran la especie de pulga en cuestión y su ecología. Esta falta de reconocimiento al trabajo de Simond se hace evidente en la ausencia de cualquier referencia a estos estudios en el apartado que Manson (1898, p. 144 y ss.) dedica a la peste en Tropical Diseases, aun cuando las experiencias realizadas con las pulgas pudieran ser de extrema utilidad para reforzar su hipótesis de los insectos chupadores como transmisores de enfermedades.

Existe otro elemento que debe ser considerado para poder comprender las dificultades implicadas en esta reducción de la medicina tropical al espacio de los estudios microbiológicos de laboratorio. Como afirma Manson, existe un gran número de enfermedades tropicales parasitarias, como son los casos de las verminosis y de la filariosis. Hacia fines del siglo XIX, ciertos parásitos humanos ya eran bien conocidos. Sin embargo, los estudios de la microbiología y los estudios de la parasitología eran independientes y parecían no tener demasiadas preguntas en común para responder. Las relaciones entre parasitología y microbiología merecerían un detenido estudio que no puede ser 
realizado aquí: este estudio debería incluir los estudios de parasitología clásica, los trabajos específicamente referidos a las enfermedades parasitarias anteriores a la teoría de los gérmenes, el debate sobre la generación espontánea de las verminosis, los estudios relativos a la alternancia y maleabilidad de los parásitos, así como los estudios pasteurianos dedicados al carbón de las ovejas donde están envueltos parásitos microscópicos y gérmenes (Edler, 1999, p. 95 y ss.)

Digamos simplemente que en 1840 , fecha de edición del Traité de pathologie interne de Grisolle, uno de los autores clásicos anteriores a la teoría de los gérmenes, podemos observar una clasificación de las enfermedades que incluye en el ítem "transformaciones orgánicas y productos mórbidos accidentales", junto a los productos mórbidos accidentales internos (quistes, soriasis, vegetaciones) y externos al organismo (cálculos, cáncer, tubérculos), un sub-ítem dedicado a los animales parasitarios: tenia, vermes, gale, filaria, pulgas, piojos etc. (apud Contrepois, 2001, p. 41) como elementos que pueden caracterizar a los fenómenos mórbidos.

Delaporte (1989, p. 120) será uno de los autores que insiste en mostrar la separación entonces existente entre estos dos universos de estudio. "La parasitología clásica era la ciencia de los organismos con biótopo viviente, el estudio de los ciclos con uno o varios huéspedes a través de los cuales se transmiten los parásitos. La microbiología era la ciencia de los agentes de las enfermedades, el estudio de las causas de las alteraciones orgánicas y las afecciones. La parasitología y la microbiología no tenían el mismo objeto de estudio." Pero, existe un elemento importante en la parasitología clásica vinculado con el estudio de los ciclos y con el pasaje de un huésped a otro: la llamada "alternancia de generaciones".

Karl Theodor Ernest von Siebold funda en 1852 la Revista de Zoología Científica. Alli se destacan los aportes de Siebold sobre parasitología, la critica a las teorías clásicas de la generación espontánea de los gusanos pero, fundamentalmente, los estudios relativos a la alternancia de generaciones de gusanos intestinales. Ensayó experimentos tendientes a mostrar la relación entre ciertas enfermedades parasitarias que, hasta entonces, eran observadas como independientes entre sí. "Probó que los parásitos que colándose en el encéfalo de la ovejas producen la enfermedad llamada 'modorra' son realmente un estadio adolescente de un gusano plano que vive en el intestino del perro. Si los perros se alimentan de los sesos de ovejas infectadas de Coenurus se infectarán infaliblemente con ese platelminto que se llamará Taenia coenurus" (Nordenskiöld, 1949, p. 477). Queda así evidenciado un hecho que será determinante para el desarrollo posterior de la medicina tropical, pues si los parásitos revisten una variedad de formas diferentes que se alternan en diversos momentos de su ciclo vital, entonces no es posible reducir la variedad de formas vivas microscópicas a la morfología simple de una bacteria. 
Aunque las enfermedades parasitarias fueran, entonces, bien conocidas, los parásitos microscópicos y su variabilidad generaban nuevos problemas y desafíos.

A diferencia de las bacterias animadas de un movimiento automático indefinido, los protozoarios como la ameba o los gusanos tienen la ventaja de sugerir, por sus movimientos, su naturaleza de agresores. En el medio de los glóbulos rojos, cuerpos transparentes alargados, siempre activos, debatiéndose como pequeñas serpientes y nadando entre los glóbulos" (Moulin, 1999, p. 77).

Esta será la dificultad que Alphonse Laveran deberá enfrentar. Sus colegas pasteurianos no parecían estar dispuestos a aceptar que una forma viva cambiante y extremadamente móvil, como el Plasmodium, pudiera cumplir el mismo rol que los bacilos y bacterias hasta entonces conocidos como agentes causales de diferentes enfermedades.

Siendo médico militar y antes de ingresar al Instituto Pasteur, Laveran fue enviado a Argelia en 1878. Allí trabajó durante años en la búsqueda de una respuesta microbiológica para el paludismo. En 1880, descubrió que el Plasmodium no era una bacteria, como se imaginaba, sino un protozoario. Imponer esta idea no fue simple, llevó más de diez años de controversias y fuertes críticas. No podía aceptarse que este agente causal fuera tan peculiar y diferente a los ya conocidos. Desowits (Desowits, 1993, p. 168) describe estas dificultades:

El descubrimiento fue visto con desdén y descrédito. ... Anillos, filamentos que danzan. ¿Cómo puede ser tan diferente morfológicamente de cualquier otro microorganismo patógeno? Nada igual había sido visto hasta ese momento. Por otra parte, Laveran no tenía credenciales, no era nadie. Y no lo ayudaba ser un artista atroz. Los dibujos que acompañaban las notas eran de un crudo y poco convincente arte primitivo".

Benchimol (1999, p. 192), refiriéndose a este periodo histórico de candentes disputas, dirá: "La principal dificultad consistía en establecer caracteres discriminatorios consensuales para separar bacterias, algas, protozoarios y hongos."

A partir del año 1897, año en que ingresa al Instituto Pasteur, ganará, poco a poco, un enorme prestigio que culminará con el premio Nóbel de 1907 por sus estudios sobre la tripanosomiasis. A partir de su ingreso en ese instituto se dedica a investigar los protozoarios patógenos dando continuidad a sus trabajos iniciales sobre la malaria. Entonces, él había sido el primero en señalar el abismo que existía entre "la morfología simple de un bacilo y el polimorfismo esquivo del parásito que se encontraba en la superficie y no en el interior de los glóbulos rojos" (Moulin, 1996a, p. 170). Esta sensible diferencia lo llevó a levantar la hipótesis de que la malaria podía ser transmitida por mosquitos, y será esta hipótesis la que guiará los 
trabajos de Manson y de Ross. Laveran (1892, p. 405 y ss.) dedica su tiempo al estudio de dos categorías de hematozoarios: la tripanosomiasis que produce la enfermedad del sueño y la leishmaniosis.

Gran parte del monto del premio Nóbel, que ganará con estos estudios, estará destinado a crear un servicio especial del Instituto Pasteur centrado en tres secciones: protozoología, microbiología y entomología médica. Un año más tarde, en 1908, crea junto a Mesnil, la Société de Pathologie Exotique, así como el Bulletin de pathologie exotique que existe hasta hoy. Desde entonces la preocupación por las enfermedades exóticas, y el interés por el papel de los vectores, comenzará a ocupar un espacio cada vez mayor en las investigaciones de los herederos de Pasteur. En el año 1909, un año después de la fundación de la sociedad de patología exótica, serán menores las resistencias que Charles Nicolle deberá enfrentar cuando define el rol de los piojos en la transmisión del tifus, si las comparamos a las resistencias suscitadas por la hipótesis de Simond del rol que la pulga tendría en la transmisión de la peste. Es exactamente ese mismo año que Carlos Chagas descubre el papel del barbero en la tripanosomiasis americana, en un estudio que da continuidad a más de diez años de trabajos en protozoología y entomología médica.

En Francia, la articulación entre parasitología, microbiología e historia natural parece alcanzar su madurez con la creación de la Sociedad y del Boletín de patología exótica de 1908. Sus fundadores, Laveran e Mesnil, sintetizan el perfil epistemológico de esta nueva área de estudios. Laveran era un parasitólogo, además de ser un médico militar que tardíamente (diez años después del descubrimiento del hematozoario del paludismo) se integrará al Instituto Pasteur. Publica, junto con Mesnil, el Tratado de Paludismo (1898), además de Tripanosomas y tripanosomiasis (1904). Félix Mesnil (1868-1938) era zoólogo y biólogo y colaborará permanentemente con los trabajos de Laveran relativos al papel del Anofeles en el paludismo. Queda definido entonces, la que será reconocida como enfermedad tropical por excelencia: la malaria.

\section{La malaria como paradigma}

Tal parece que a partir del nacimiento de la medicina tropical o de la medicina exótica entran en juego nuevos actores que complejizan el trabajo de los bacteriólogos clásicos. Esta red de saberes parecía estar definida, al menos intuitivamente, en Inglaterra en el momento en que Manson estudia la filariosis (1877 a 1890). Entonces la filaria era un parásito ya conocido, pero restaba definir el modo de propagación de la enfermedad (se sabía que no era de contagio directo) y estudiar el ciclo evolutivo del parásito que se realiza parte en el hombre y parte en el medio externo: "Para Manson el enfermo es un impasse del cual el parásito debe escapar. Atribuye 
al parásito dos vías, de las cuales una es independiente del cuerpo humano: debe poder entrar y salir para poder cumplir su ciclo" (Moulin, 1999, p. 79).

La sospecha de que parte del ciclo vital del parásito era realizado en el mosquito posibilitó comprender la evolución de la enfermedad y su transmisión. Observando atentamente en su microscopio, Manson constata que las filarias sólo aparecen en la sangre a partir de las ocho horas de la noche y allí restan toda lo noche. Esta regularidad, imagina Manson, debe ser un elemento facilitador para el encuentro con el agente que le permite salir del cuerpo humano y ese agente deberá formar parte de los insectos chupadores de sangre; entre ellos es el mosquito quien posee hábitos que puedan ser semejantes. La hembra del mosquito no sólo permite que el parásito salga del cuerpo enfermo, también posibilita la realización de parte de su ciclo evolutivo en su interior, una vez infectada disemina los embriones en el agua que infectará al hombre en el momento de beberla (ibídem, p. 78).

Esta hipótesis sólo alcanzará fuerza explicativa años más tarde cuando, en 1897, Ross, siguiendo los insistentes consejos de Manson, decide realizar en la India estudios sobre el insecto transmisor del paludismo tomando como punto de partida los estudios de Laveran, tanto el descubrimiento del protozoario como su hipótesis de que un determinado mosquito tendría un rol central en la propagación del paludismo (Manson, 1898, pp. 2, 7, 15; Manson, 1998, p. 83).

Antes de la creación del instituto de Patología Exótica del Instituto Pasteur, Manson ya conocía, y muy bien, los trabajos de Laveran sobre el paludismo, no sólo aceptaba la existencia del Plasmodium, sino también coincidía con él en la hipótesis del mosquito como vector intermediario. Tomando como punto de partida estos descubrimientos de Laveran, y considerando la similitud entre la hipótesis de un mosquito que actuaría como intermediario con los estudios por él realizados sobre filariosis, Manson impulsará a Ross para iniciar una serie de estudios en la India tendientes a corroborar o refutar esa hipótesis. Existe un interesante registro de las dificultades que Ross debió atravesar hasta llegar al premio Nóbel que, en 1902, le sería concedido por el descubrimiento del papel que el Anofeles desempeña en la propagación del paludismo aviario. Todas y cada una de esas dificultades son relatadas con la pasión, el temor y las dudas que entonces existieron en la mente de estos hombres simples, ambiciosos y nacionalistas, en la correspondencia que ambos mantuvieron entre los años 1894 y 1899, pasando por el gran día del descubrimiento o "The Mosquito Day", como Ross prefería llamarlo a ese 20 de agosto de 1897 (Bynum y Overy, 1998, p. 385).

Estas cartas, que fueron cuidadosamente conservadas y archivadas, constituyen hoy una fuente invaluable para poder comprender algo más sobre las enfermedades tropicales. Estas cartas hablan sobre la 
malaria y el Plasmodium, hablan insistentemente de la hipótesis del mosquito Laveran (Manson, 1998, p. 83), de los investigadores italianos, también de los miedos que un investigador poco preparado en los estudios de entomología debe enfrentar para poder reconocer entre la multiplicidad de insectos chupadores de sangre a aquel que pudiera servir como vehículo y agente intermediario del paludismo, a aquel que posibilitara que parte del ciclo vital del Plasmodium pudiera realizarse en su interior. Muchas dificultades son relatadas: expectativas que parecen estar siempre frustradas, miedo al fracaso, necesidad de encontrar este insecto antes que los investigadores franceses o italianos lo hagan, resultados confusos, falta de claridad en los objetivos etc.

Las cartas revelan el lado humano de los investigadores, y por eso su riqueza. Hablan de la ayuda que uno y otro se prestaron, hablan de los mosquitos que atraviesan el mar conservados en glicerina para ser observados por Manson, de los análisis y estudios comparativos, de la colaboración entre dos intelectuales que persiguen un mismo objetivo. Pero, revelan también las miserias de la medicina imperial, las mentiras dichas a los supuestos voluntarios, relata las experiencias con mosquitos infectados que llevaron a la enfermedad y a la muerte, hablan, en fin, de la liviandad y la falta de humanidad con la que eran tratados los pueblos colonizados. Las cartas, nos revelan, en fin, la trastienda, aquello que no se dice, aquello de lo que no se habla en la clásica y heroica historia de la medicina.

Estas cartas revelan, también, por qué la malaria, a pesar de ser una enfermedad que no se limita geográficamente a los trópicos, debe ser considerada como el paradigma de la enfermedad tropical. Esta correspondencia fue reunida por Bynum y Overy (1998, p. 120) en un texto que lleva el sugerente nombre de 'La bestia en el mosquito'. Esta era la misión que, como se enuncia en la carta 13, Manson le diera a Ross: instalarse en la India con la finalidad de encontrar la bestia (el plasmodioum) en el mosquito (Anopheles). Es entonces, en el "Mosquito Day" que el rompecabezas finalmente parece cerrarse. Hoy sabemos que aún serían necesarios los estudios de Grassi sobre la malaria humana, pero, sin embargo, este hecho no le resta valor a este relato que puede ser leído como la historia no contada de la malaria. Es entonces que la tenue línea que separa la historia interna de los descubrimientos científicos realizados en la asepsia del laboratorio, con protocolos bien delineados y diseños de investigación que se definen como imparciales y objetivos, se mezcla con la otra historia, la historia de los miedos humanos que están por tras de un descubrimiento científico, el miedo de los enfermos, de los voluntarios, de los investigadores, las alianzas, las mentiras, la falta de preparación de los investigadores, en fin, aquello que no puede ser publicado en The Lancet.

Podríamos imaginar que estas cartas revelan una cierta irracionalidad de la investigación científica, podríamos afirmar con 
${ }^{3}$ Recordemos aquí que el concepto de paradigma de Thomas Kuhn (1971, pp. 268319) posee dos significados bien precisos que serán definidos en la posdata de la edición de 1969 de La estructura de las revoluciones científicas. Allí define paradigma en el sentido de matriz disciplinar (el sentido más usados por los kuhnianos) y otro sentido que es el de ejemplar. Es en este segundo sentido que hablamos aquí de paradigma, esto es: "realizaciones científicas reconocidas universalmente que, durante cierto tiempo, proporcionan modelos de problemas y soluciones para una comunidad científica" (ídem, p. 13).
Bruno Latour (1997, p. 102) que ellas dejan trasparecer las limitaciones y falta de objetividad de un estudio que nos sitúa, una vez más, frente a la relatividad y precariedad del saber científico. Preferimos, por el contrario, aceptar las tesis de Pierre Bordieu (2001, p. 55) y observar estos documentos como elementos que pueden contribuir a comprender mejor una conquista científica muy puntual pero de enormes consecuencias en el ámbito de los estudios dedicados a la medicina tropical.

Es que, el descubrimiento de Ross del mosquito transmisor del paludismo aviario resulta un modelo de investigación que será diversas veces aplicado para dar respuesta a los diferentes desafíos sanitarios que la vida en las colonias impone. El paludismo parece ser un paradigma $^{3}$ que puede auxiliar, de manera directa o indirecta, al descubrimiento de la transmisión de múltiples enfermedades tropicales, como la fiebre amarilla, la enfermedad del sueño, las leichmaniosis o la enfermedad de Chagas. Esto significa que, cuando nos detenemos a analizar las dificultades de ese descubrimiento, tanto aquellas asociadas a la aceptación (que como dijimos demoró más de diez años) del Plasmodium, como aquellas relatadas en las cartas de Ross y Manson para determinar el papel de un mosquito en particular en esa transmisión, parece que estamos frente a un rompecabezas cuyas partes fueron unidas por azar. Parece que son más los errores y los fracasos que están por detrás de esta conquista que una historia de triunfos cuidadosamente programados.

Observando lo no dicho en los textos formales, los pequeños errores del laboratorio, las pipetas rotas, los datos equivocados, Latour (1997, p. 46 y ss.) concluye que: "La realidad artificial que los participantes describen como una entidad objetiva, ha sido, de hecho, construida." A partir de esa constatación, que no tiene nada de novedosa para la tradición bachelardiana, Latour lleva al límite su relativismo radical dejando entender que "por ser artificiales, fabricados, los estudios de laboratorio son ficticios, no objetivos y no auténticos" (Bourdieu, 2001, p. 56).

La pretensión de Bourdieu está lejos de esta estrategia de Latour de transformar las construcciones históricas en hechos irrelevantes y sin objetividad. Este autor pretende mostrar que es necesario observar dos niveles del discurso científico. Un discurso formal, que se vale de la forma impersonal, reduciendo al mínimo las intenciones de los investigadores. En ese momento el investigador se omite para dejar "hablar los hechos". Nos referimos, claro, a las publicaciones en revistas científicas.

Pero hay otro nivel de discurso, y en ese podríamos incluir las cartas de Manson y Ross. Nos referimos al discurso privado, donde aparece lo que no puede ser publicado. Este discurso ya no es impersonal, aquí hay tomadas de partido, acusaciones, se ponen en evidencia los errores y los abruptos cambios de marcha que la 
${ }^{4}$ La utilización indiscriminada de pacientes internados como objeto de investigación no fue exclusiva de los institutos europeos en sus colonias de ultramar. Benchimol (1999, p. 35) señala que el uso de pacientes como cobayos no despertaba, entonces, ninguna indignación y era considerado como un hecho natural también para los investigadores brasileros como

Domingos Freire. Resulta significativo el contraste que este autor destaca entre la banalización de esos experimentos y la irritación que provocaba el uso de animales para investigaciones semejantes. investigación se ve forzada a tomar. A veces este discurso circula dentro del laboratorio de modo más o menos sutil y el sociólogo de la ciencia que allí ingresa debe explicitar aquello que ocurre de modo secreto. La historia de la ciencia se ha centrado, clásicamente, en los relatos formales, ocupándose del discurso privado sólo para exaltar el heroísmo, la voluntad o el valor de los grandes hombres de la ciencia. Por el contrario, las competiciones, los errores, los fracasos y cambios de marcha tendieron clásicamente a ocultarse.

Existe un carácter inseparablemente científico y social de la investigación científica, y es ese doble carácter que debe ser observado en la correspondencia Manson-Ross. Una muestra de ese carácter doble podemos encontrarla en la carta 27 que Manson envía a Ross el día 11 de octubre de 1895. Allí leemos: "Laveran está inclinado a tomar la hipótesis del mosquito y no tengo dudas de que en el próximo verano los franceses y los italianos trabajarán en eso. Entonces por Dios dese prisa y salve los laureles de Inglaterra!!" (Manson, 1998, p. 83). Dos años más tarde, el 20 de agosto de 1897, en aquel que dio en llamar el "Mosquito Day", Ross conseguirá salvar el honor inglés que tanto se temía perder. Es claro que estos laureles llegarán con toda la honra que la situación requiere. Esto es, con el premio Nóbel concedido años más tarde a Ross. Ciertamente, para conquistar estos laureles, parecía que todo estaba permitido. Aun el engaño y la mentira como leemos en la carta 203, cuando Ross (1998, p. 385) relata que le había afirmado a un voluntario que la picadura de un mosquito infectado con malaria lo ayudaría en su recuperación y lo liberaría definitivamente de los parásitos de la malaria.

Lo cierto es que, independientemente de las miserias humanas también presentes en los abusos experimentales ocurridos con estudios realizados por los pasteurianos en las colonias de ultramar, ${ }^{4}$ la malaria aparece como un caso ejemplar o paradigmático en el que, por primera vez, coinciden una diversidad de saberes que hasta ese momento tenían desarrollos independientes, como la helmintología, la protozoología, la microbiología, la clínica y la entomología. De un modo que bien podemos definir como intuitivo, las dificultades encontradas obligaron a Ross a desistir del estudio del paludismo humano para ocuparse del aviario. Él debió convertirse lenta y pacientemente, durante sus años de trabajo en la India, en un helmintólogo y en un entomólogo. Inicialmente, y como lo demuestran sus primeras cartas, Ross parecía tener una preparación técnica deficiente en estas áreas. Así, por ejemplo, en la segunda carta leemos: "Todas mis larvas de mosquitos murieron debido a mi tontera de poner las botellas en el sol. Tuve que comenzar, consecuentemente, un nuevo grupo: pero es vergonzoso" (Ross, 1998, pp. 3, 91); o en la carta 31: "Temo decepcionarlo nuevamente sobre los especímenes. Manipulé los mosquitos, pero probablemente debido a las bajas temperaturas ellos se negaron nuevamente a picar." 


\section{De la aclimatación y biogeografía}

Si tomamos como punto de partida para este estudio los trabajos de Manson, esto no significa afirmar que es entonces que se inician los estudios de medicina tropical. Ciertamente, existen múltiples y valiosos estudios relativos a la parasitología y a las enfermedades propias de los climas cálidos que configuran la condición de posibilidad de los estudios mansonianos. Sin embargo, creemos que es posible señalar una novedad en el discurso de Manson que debe ser analizada independientemente de cualquier intención o pretensión de volver a una historia clásica fundada en la exaltación de los grandes nombres. El año de 1898 señala un momento histórico ambiguo. Para muchos representa el inicio de la medicina tropical y para otros no es más que un dato irrelevante y aislado en una larga cadena de estudios dedicados a las enfermedades tropicales. En este trabajo pretendimos mostrar que un análisis detallado del modo como es conceptualizada la medicina tropical en Tropical Diseases (1898) puede representar, sí, la inauguración de un nuevo programa de investigación heredero, por un lado, de la teoría de los gérmenes o microbiología y, por otro, de la tradición naturalista y sus estudios de helmintología, parasitología y entomología. Pero, si hablamos de cierta novedad es porque queremos destacar que existe cierta distancia entre el programa de investigación mansoniano y los protocolos de investigación clásicamente utilizados por ambos.

Quizás no sea el concepto de paradigma kuhniano y sí el concepto de "programa de investigación" de Lackatos (1983, pp. 65-72) quien más nos auxilie a comprender el estatuto epistemológico de la medicina tropical. Este programa de investigación es heredero directo de los estudios de la microbiología y la parasitología, pero exige protocolos de investigación irreductibles a aquellos que, hasta entonces, definían el modo esperable de acción (la ciencia normal en palabras de Kuhn) de bacteriólogos, por un lado, y naturalistas, por otro (debemos recordar que la historia natural no se limitaba a describir, inventariar y clasificar especies, que entre los historiadores naturales existían múltiples problemas como la evolución de especies, su transformación, su localización geográfica, sus correlaciones y alianzas etc. y que, para ello, se valían también de estudios experimentales y de laboratorio que no eran idénticos a los realizados en los laboratorios de los

${ }^{5}$ Ver a este respecto el capítulo dedicado a la emergencia de la helmintología médica en Edler (1999, pp. 94-111). bacteriólogos). ${ }^{5}$

Resulta esencial, y este no es un dato secundario, analizar detenidamente la función de los institutos Pasteur de ultramar y los objetivos que persiguieron las misiones científicas en las colonias. Recordemos que "la emergencia y el desarrollo de la microbiología fue contemporánea a la expansión colonial francesa. Por una coincidencia cuyas consecuencias son incalculables en el mismo momento en que la expansión europea aumenta, Pasteur llega al punto culminante de 
su obra" (ibídem, p. 14). ¿Qué es lo que esto significa? Que las conquistas pasteurianas serán trasladadas inmediatamente a las colonias y es por eso que la primera misión de los institutos de ultramar será la multiplicación de centros de producción de vacunas antirrábicas. Así, en 1887, ya se contará con 14 institutos de producción de vacunas en el mundo. Paralelamente, "por un movimiento centrífugo iniciado por el Instituto Pasteur de París se dio una diseminación de modestos laboratorios de bacteriología, centros de tratamiento antirrábico, y también centros de producción de vacunas". Si la rabia es la primera preocupación de los institutos Pasteur de ultramar, la segunda será la viruela, otra enfermedad cosmopolita. Como afirma Dedet (ibíbem, p. 18): "la vocación primera de los institutos Pasteur de ultramar era la difusión del tratamiento antirrábico de Pasteur". Por otra parte la producción de la vacuna antivariólica dio inicio a la creación de la gran mayoría de los institutos de ultramar, posibilitando la total erradicación de la viruela de Madagascar en 1914.

Es verdad que rabia y viruela no fueron las únicas enfermedades que preocupaban a estos institutos. En 1883 se envía una misión a Egipto para estudiar el cólera. En 1893 será creado el Instituto de Saigón que tendrá por misión el estudio de la peste. La malaria será el centro de los esfuerzos en Argelia a partir de 1890. Pero, debemos recordarlo una vez más, los trabajos de Laveran sobre el Plasmodium son independientes de los trabajos del instituto; los trabajos de Simond fueron poco considerados por sus colegas. Sólo más tarde (1905-06), el Instituto Pasteur comienza a preocuparse por la fiebre amarilla (misión enviada a Brasil) y la enfermedad del sueño (misión enviada al Congo). Hasta ese momento, la tarea de los institutos fue conjugar la asistencia, la higiene y los estudios bacteriológicos: aislar microorganismos, cultivarlos, producir vacunas y sueros.

La lectura de Tropical Diseases parece evidenciar que la preocupación de Manson no era exactamente la misma. Ambos comparten un mismo objetivo: hacer de los trópicos un espacio saludable y habitable para el hombre blanco. Pero, ambos trazan caminos de investigación e imaginan estrategias de intervención diferentes. Manson observa que un gran número de enfermedades tropicales son parasitarias y dependen de complejas cadenas de transmisión que envuelven huéspedes intermediarios vivos donde realizan parte de su ciclo vital. Como ya fue discutido, comprender la especificidad de la medicina tropical exige "distinguirla de la bacteriología" (Bynum y Overy, 1998, p. ix).

Pero, comprender la especificidad de la medicina tropical exige algo más. Si por una parte este espacio de saber se diferencia del modelo de investigación de los pasteurianos de ultramar, por otra parte, se trata de un programa de investigación que se distancia también de los estudios clásicamente dedicados a las enfermedades de los climas tórridos y esto porque el clima pasará a ser considerado por 
Manson como un dato indirecto y hasta secundario en la producción de las enfermedades. Si preferimos hablar de programa de investigación, en lugar de paradigma, es porque la medicina tropical no constituye un campo disciplinar unificado bajo un paradigma único, sino que, desde su inicio resulta del encuentro de diferentes campos de investigación que se articulan en torno de una problemática común. Así, el programa de investigación inaugurado por Manson convive y compite con otros programas que, en diferentes circunstancias, pueden resultar más o menos exitosos.

Señalamos ya algunas diferencias con los pasteurianos de ultramar. Resta analizar de qué modo el programa de investigación se diferencia de los estudios dedicados a las enfermedades de climas tórridos. Recordemos que al intentar explicar la peculiar distribución de ciertas enfermedades tropicales, Manson (1898, p. xv) adoptará una posición que sólo puede ser comprendida en el interior de las explicaciones biogeográficas próximas a la tradición darwiniana: "gérmenes de enfermedades, sus agentes de transmisión, o sus huéspedes intermediarios, son, durante su fase extracorporal, necesariamente, organismos competidores, y de este modo susceptibles de ser capturados por predadores, o destruidos por otros organismos en la lucha por la existencia". Es así que, en nuestro conocimiento sobre enfermedades tropicales puede resultar menos importante el rol de la temperatura y del calor que la influencia que ejercen los posibles predadores sobre los parásitos, vectores y microorganismos. "Cuanto más aprendemos de estas enfermedades, el rol de la temperatura per se deviene menos importante en la determinación de su distribución geográfica y cobra mayor importancia la fauna tropical."

Los argumentos presentados en Tropical Diseases se distancian del modo como clásicamente fue pensado el papel del clima tórrido como multiplicador de miasmas o como agente que interviene directamente en los procesos de putrefacción; también se distancia de los estudios realizados por los médicos militares de las colonias y los naturalistas miembros de la Société d'Acclimatation que desde el año 1850 concentraban sus esfuerzos en el Jardín de Aclimatación de París.

Es posible que la diferencia entre el programa mansoniano de investigación y los estudios realizadas por esas sociedades preocupadas por las colonias de ultramar, que publicaban sus ideas en revistas tales como la Revue Maritime et Coloniale (1861-98) o la Revue Algérienne et Coloniale (1859-60), pueda ser comprendida por referencia a la coexistencia de dos formas diferentes de investigación en la tradición de los naturalistas. Por un lado, una amplia variedad de estudios zoológicos, antropológicos y geográficos que dialogaban con el aclimatacionismo, por otro, los estudios de biogeografía que eran particularmente fuertes en la Inglaterra pre y pos darviniana. 
${ }^{6}$ Ciertamente, como afirma Bourdieu (1982, p. 229), la "teoría de los climas es, en efecto, un paradigma remarcable de la mitología científica; un discurso fundado en la creencia (o prejuicio) que oscurece la ciencia y que se caracteriza por la coexistencia de dos principios

entremezclados de coherencia: una coherencia proclamada, de origen científica y una coherencia oculta, mítica en su origen"
Para poder comprender esta diferencia resulta esencial que nos interroguemos por el concepto de pesimismo climático. Tal como fue analizado por Pierre Bourdieu (1982, pp. 227-39), ese pesimismo tiene su origen en la teoría de los climas que Montesquieu presenta en $E l$ espiritu de las leyes para responder a la pregunta "¿La diferencia de climas en que nacen los hombres, contribuye a las diferencias en su espíritu?" ${ }^{2}$ Es preciso resaltar que la tradición médica que imaginaba que el calor y la humedad de los trópicos condenaban necesariamente a la enfermedad y al fracaso poco a poco desaparecerá para dejar lugar a un nuevo modo, más sutil, de pesimismo climático que ya no hablaba de condena sino que entendía que esa "alteridad radical" representada por los trópicos podía ser, poco a poco y con ciertas estrategias bien puntuales, modelada según moldes civilizadores e higiénicos. Los trópicos parecían estar marcados por la diferencia, pero esa diferencia no era valorativamente neutral. Estaba, por el contrario, cargada de marcas y signos que parecían indicar que, con la intervención de estrategias aclimatacionistas puntuales, los trópicos podían ser habitables por los colonos europeos.

Muchos naturalistas europeos adoptaron estas ideas aclimatacionistas que eran particularmente fuertes en Francia. Grandes naturalistas, como Cuvier o Isidore Geoffroy de Saint-Hilaire, persiguieron objetivos aclimatacionistas. Para ellos "aclimatar un individuo, raza o especie, después de haberla transportado a otro país, es decir, fuera de su armonía natural, es habituarlos a la nueva condición de existencia y generar que conquisten la armonía con el nuevo medio" (Osborne, 1994, pp. 63, 77). Pero, no es posible hablar de una teoría aclimatacionista única. La Sociedad Aclimatacionista reunía una variedad de temas, perspectivas y métodos, extremadamente amplia, y a veces contradictoria. Sin embargo, todas compartían una misma preocupación por determinar los efectos que el clima tórrido podía tener en la flora, fauna o aun en las poblaciones, $\mathrm{y}$ muchas veces los debates giraron en torno a una cuestión privilegiada: la existencia de cierta variabilidad natural (más o menos restricta) del así llamado tipo originario de la especie en relación al nuevo medio.

Para ellos, la adaptación a un nuevo espacio geográfico estaba vinculada exclusivamente con la capacidad, natural o adquirida, de poder sobrevivir a las diferencias climáticas, y esa capacidad estaba directamente vinculada con la idea de variabilidad del tipo específico que, a diferencia de lo que ocurre en la perspectiva darwiniana, significaba preeminentemente variaciones fisiológicas que ocurrían en el plano del organismo de un individuo sometido al proceso de aclimatación. Existían, entonces, aclimacionistas más o menos pesimistas y esto se verificaba con mayor claridad cuando se dejaban de lado las variaciones zoológicas para pensar en la aclimatación de hombres y pueblos. Entre los más pesimistas encontramos a Rochard (1886, p. 655). Para él, existía una dificultad constitutiva para que el 
hombre europeo blanco pudiera habitar las regiones tropicales: "En los países cálidos más salubres, la estadía puede prolongarse algún tiempo, pero las fuerzas van agotándose poco a poco y el europeo que se destacaba por su actividad y su ardor al trabajo, ve, poco a poco su vigor declinar, sus fuerzas decrecer. Él es invadido por la anemia de los países calientes que no le dejará más que los deseos de vivir si él no se dirige para su cura a un cielo menos ardiente."

Pero, no todos los aclimatacionistas presentan este cuadro fatalista y determinista. Lo cierto es que para algunos, la perniciosidad del clima tórrido representa también un problema, pero un problema soluble y no una maldición, pues, según entienden, es posible superar esas dificultades con estrategias específicas de adaptación climática, tal es el caso de Boudin, aclimatacionista defensor de ideas cosmopolitas que se opone frontalmente a las tesis de Quatrefages sobre la influencia perniciosa del medio (Osborne, 1994, p. 93).

Estas ideas aclimatacionistas, solidarias de las promesas de reforma y de purificación de los trópicos, parecen estar presentes en el discurso de los higienistas, naturalistas y médicos militares franceses. Por el contrario, la biogeografía, esto es, el estudio de la distribución geográfica de diferentes formas de vida, iniciado en 1830 con Principles of Geology de Charles Lyell (Bowler, 1998, p. 201; Rehbock, 1983, p. 119 y ss.), parece ser el complemento indispensable de los estudios realizados por los médicos militares ingleses.

Podemos comprender el objetivo de esta disciplina a partir de esta referencia de Camille Limoge (1976, p. 64): "En 1835, un artículo anónimo sobre la distribución geográfica de los insectos fijaba los objetivos de esta nueva disciplina: (a) establecer las proporciones del número de especies de acuerdo con las regiones climáticas; (b) establecer las proporciones del número de especies en relación con los géneros." Este artículo, llamado "Thoughts on the geographical distribution of insects', fue publicado en el Entomological Magazine de Londres y Darwin hará referencia a él en el Origen de las especies. La biogeografía se caracterizaba por tomar como punto de partida para sus investigaciones cierta neutralidad valorativa en relación al clima, limitándose a describir y a intentar comprender la diversidad y la complejidad de lo vivo. Los primeros biogeógrafos tenían el objetivo de establecer estadísticas de distribución de las especies (Humboldt), luego, sus seguidores, entre ellos Darwin, intentarán dar explicaciones de esos fenómenos que no se limiten al factor climático (Limoge, 1976; Bowler, 1998).

Mientras los aclimatacionistas pretendían multiplicar los esfuerzos por comprender y reducir lo otro (la colonia) a lo mismo (la identidad con la metrópoli); la biogeografía parece instaurar un programa de investigación que (a pesar de mantener intacta la crueldad experimental propia de ese periodo) parece realizar un esfuerzo por comprender la 
variedad de los seres vivos propios de los climas tórridos así como las complejas interacciones biológicas existentes entre unos y otros.

Es así que en el mismo momento en que Rochard critica el optimismo aclimatacionista de sus colegas franceses, Manson parece desplazar su atención desde la peligrosidad climática hacia la diversidad biogeográfica de los seres vivos, intentando comprender sus alianzas y luchas. Sin desestimar las conquistas que la higiene pública, con sus clásicas medidas de saneamiento, desinfección y vacunación, representaba para las enfermedades cosmopolitas, la medicina tropical inglesa pretendía entender los procesos de interacción entre los seres vivos, y para comprenderlos tanto el clima como los procesos de aclimatación ocupaban un lugar secundario. En este punto Manson coincide absolutamente con Darwin. Manson manifiesta su asombro delante de la sutil eficacia de las adaptaciones biológicas cuando estudia la filaria. Encuentra en este caso lo que él llama de un "ejemplo de periodicidad". "Puede ser claramente observado que la variación día-noche en la presencia de filaria en la sangre humana era una adaptación cuyo propósito consistiría en incrementar el ajuste del mayor desarrollo de la filaria con los mosquitos que pican de noche. Es este argumento teleológico, como afirman Bynum y Overy (1998), que será reiterado en el caso de la malaria, lo que aproxima a Manson de la preocupación darwiniana por las complejas relaciones "mutuas entre animales y plantas en la lucha por la existencia" (Darwin, 1984, p. 125). Podemos decir que, para ambos, toda función biológica tiene un significado, existe un dictado que debe guiar el razonamiento de los investigadores, y que Manson (1998, p. 92) enuncia en la carta 32 como sigue: en las interacciones biológicas nada ocurre porque sí.

Más que asociar esta idea a la teología natural podemos aproximarla a la teleología naturalizada por la mediación del darwinismo (Sober, 1993, p. 82). En este último caso, las complejas interrelaciones entre los seres vivos son aquellas que mejor responden a las exigencias de la selección natural, esto es a la exigencia de reproducción de las especies. Y este razonamiento no sólo se aplica a los grandes animales sino también a los parásitos, y a los microorganismos en general. Desde esta perspectiva, la amenaza representada por los predadores y el conocimiento de la biogeografía desplazan en importancia al clima y a la preocupación por el aclimatacionismo.

Es verdad que tanto Darwin como Manson se refieren al papel del clima, aunque para ambos su rol es secundario y subsidiario. Así, para Darwin (1984, p. 123):

Cuando viajamos de norte a sur, vemos que algunas especies van siendo cada vez más raras y que, por fin, desaparecen; y como el cambio de clima es bien notorio, atribuimos todo el efecto a su acción directa. Pero, ésta es una idea errónea; olvidamos que cada especie, aun donde es 
muy abundante, sufre constantemente una enorme destrucción en algún periodo, a causa de enemigos o de competidores por el mismo lugar y alimento; y si entonces, enemigos o competidores son favorecidos, aun en el más ínfimo grado por cualquier leve cambio de clima, aumentará el número y como cada área está ya completamente poblada de habitantes, las otras especies tendrán que disminuir ... El clima actúa sobre todo indirectamente, favoreciendo otras especies.

Manson (1898, p. xv) dirá, de manera semejante, que "cuanto más aprendemos sobre las enfermedades tropicales, menos importante nos acaba pareciendo la temperatura per se como agente patogénico directo y como explicación de su distribución geográfica"; y, en contrapartida, "más importante deviene la influencia de la fauna tropical".

En relación al papel de la aclimatación, encontramos también un razonamiento semejante. Ambos, Manson y Darwin, consideran que los fenómenos de aclimatación no pueden ser pensados de modo unívoco, pues la posibilidad de transplantar una especie de un lugar al otro no depende solamente de la capacidad de tolerancia al nuevo clima sino también de los nuevos competidores y amenazas que deberán ser enfrentados, así como de la capacidad natural o adquirida de crear hábitos de vida compatibles con el nuevo medio.

La preocupación de Darwin (1984, p. 197) estaba centrada en la aclimatación de plantas y animales domésticos. Así, en el Origen de las especies, al referirse al ítem aclimatación', afirma:

Es notorio que cada especie está adaptada al clima de su propio país. Pero se exagera a menudo el grado de adaptación de las especies a los climas en que viven. Podemos deducir esto de nuestra frecuente incapacidad para predecir si una planta importada resistirá o no nuestro clima, y del número de plantas y animales traídos de diferentes países que viven con perfecta salud. Tenemos motivos para creer que las especies en estado de naturaleza están estrictamente limitadas a sus áreas por la competencia de otros seres orgánicos, tanto más que por la adaptación a sus climas particulares.

Señalemos simplemente la diferencia radical que separa a este razonamiento de aquel que motivara, a partir de 1850, la creación del jardín de aclimatación de París. El interés exclusivo que existía en relación a este jardín era de orden climática, allí las especies podían ser observadas y presentadas al público, pero ya no en lo que sería su nuevo estado natural sino bajo ciertos límites y en un determinado espacio bien controlado. La prioridad era concedida a la adaptación climática y la observación de predadores naturales potenciales era desconsiderada.

La preocupación de Manson no era tanto la aclimatación de plantas o animales domésticos como, fundamentalmente, la aclimatación de los extranjeros a los trópicos, particularmente en 
aquellas regiones donde existía la malaria. Para intentar comprender este fenómeno, analizará las conductas peligrosas de los recién llegados confrontándolas con los cuidadosos hábitos de los antiguos residentes. Muestra que los antiguos residentes han recibido una educación para poder enfrentar los peligros existentes, que esta educación ha creado en ellos hábitos de vida que les permiten preservarse de las amenazas externas. Así, es posible protegerse del calor excesivo, evitando salir en determinadas horas del día, de los mosquitos, de las corrientes de aire, de los lugares húmedos, de la comida y la bebida excesivas etc. "Duras lecciones llevan al recién llegado a respetar el sol y la lluvia y el viento, a vestirse para evitar la fiebre, a vivir con moderación. Aclimatación, en sentido amplio, significa experiencia y educación; no solamente una adaptación inconsciente de la fisiología del individuo sino una adaptación inteligente de sus hábitos" (Manson, 1898, p. 103). En fin, crear un conjunto de estrategias adaptativas de carácter, ya no biológico, sino cultural y social.

Resulta evidente la oposición de este concepto de aclimatación con aquel defendido por Rochard (1886, p. 661), al que ya nos referimos: "la raza blanca no ha podido jamás establecerse y apropiarse del suelo en las zonas de clima tórrido". Y sin embargo ambos hablan de aclimatación. Quizás podamos concluir, siguiendo a Quatrefages, que existe una ambigüedad inherente al concepto de aclimatación que lo convierte en un dominio de estudios múltiples y muchas veces contradictorios. Pero si Darwin y Manson pueden ser aproximados epistemologicamente, esto es, no por citaciones explícitamente enunciadas, sino por argumentos semejantes, es porque ambos descreen del poder absoluto del clima para explicar la diversidad de las especies y la peculiar localización, en el caso de Manson, de ciertas enfermedades. Porque ambos reparan para el modo de distribución geográfica de las especies, insistiendo en la necesidad de observar la complejidad de sus interacciones. Porque, en ambos casos, la importancia teórica de la biogeografía parece sustituir la confianza del aclimatacionismo.

Por fin, y en la medida en que las enfermedades tropicales nos indican un tipo peculiar de configuración entre los seres que incluye, seres humanos, insectos, parásitos y microorganismos, y en la medida que requiere una detenida observación del ciclo evolutivo y reproductivo de estos seres y de las condiciones climáticas y biológicas (predadores) esenciales para su reproducción, la medicina tropical parece introducir un nuevo elemento irreductible a la historia natural y a la microbiología: la diversidad de modos en que el así llamado hombre europeo blanco y los nativos se enfrentan con esa compleja cadena de seres vivos, el saber intuitivo y eficaz de los segundos, frente a la vulnerabilidad y falta de resistencia de los primeros. 
Dicho de otro modo, la emergencia de la medicina tropical nos sitúa frente a la sustitución (y por momentos a la convivencia) de un programa de investigación preocupado por reducir lo desconocido a lo conocido, lo otro a lo mismo, por un nuevo programa, heurísticamente más fructífero, preocupado fundamentalmente por el conocimiento de la diversidad de los seres vivos. En el primer caso la bipolaridad de ese programa de investigación adopta dos modalidades diferentes: la extensión de los laboratorios metropolitanos a las colonias y la preocupación por la aclimatación de las especies tropicales al clima templado. En el segundo caso se delimitará un programa preocupado por las complejas cadenas que unen y separan los seres vivos, esto es, por la pluralidad de lo viviente. Esta complejidad exige nuevos protocolos de investigación irreductibles a los ya conocidos aunque, claro está, deba nutrirse de los protocolos de investigación provenientes de las diversas áreas que se articulan en ese programa en torno a un eje común: las enfermedades tropicales.

Sería ingenuo imaginar que este programa surge de una vez y para siempre con Manson. Como vimos fueron muchas las tentativas y errores, pero, lo cierto es que, los trabajos de Manson, Laveran y Ross definen un nuevo dominio de investigación que torna explícita la necesidad de integrar múltiples investigaciones que estaban siendo realizadas en diferentes campos, la clínica, la biogeografía, la entomología, la protozoología y la microbiología con la cuidadosa observación de los conocimientos locales relativos a las enfermedades. Este programa se demostró fructífero para el estudio de esas enfermedades parasitarias que precisan de vectores para su propagación aun cuando, en 1898, fecha de publicación de Tropical Diseases (Manson), pudiera pensarse en estos términos solo unas pocas enfermedades como la malaria o la filariosis, y no la dengue o la enfermedad del sueño o la fiebre amarilla.

Aunque, según parece derivarse de la lectura de los textos, es Manson quien mejor define la novedad de este programa de investigación. Es cierto que cuando éste fue enunciado existían dificultades y extensiones indebidas a un número sorprendentemente grande de enfermedades. Así, para Manson (1898, p. 128), el modelo parásito-vector daría respuesta a enfermedades tan diferentes como cólera o beriberi. Él persistió en su deseo de intentar definir estas enfermedades según el modelo de la malaria, cuando hipótesis auxiliares le permitieran reforzar su programa. Como afirma Ian Hacking (1985, p. 247):

Cuando todo lo demás hubo fallado, y empezábamos a saber que el beriberi era causado por falta de algo como consecuencia de pulir el arroz, Manson dijo que había escarabajos que vivían y morían en el arroz y que ellos causaban el beriberi. Hipótesis auxiliares continuamente están cerrando y excluyendo contraejemplos, mientras un programa progresivo puede responder con poderosas predicciones nuevas, algunas de las cuales resultan ciertas. Pero sólo a posteriori podemos saber cuál es progresiva y cuál es degenerativa. 
Es claro que Manson (1898, p. 129) no define de una vez y para siempre ese programa de investigación; existen dificultades e hipótesis que más tarde se demostrarán falsas como la hipótesis del beriberi o la suposición de que el germen de la fiebre amarilla requiere de cambios en su desenvolvimiento extracorporal que lo inhabilitan para atacar o para vivir en el cuerpo humano nuevamente. Sin embargo y aun cuando una historia epistemológica retrospectiva nos permita observar que estas y otras hipótesis auxiliares fracasaron, podemos, sí, hablar de un programa de investigación que demostró ser heurísticamente fértil. Si entendemos por programa no una teoría acabada sino una serie de teorías que se suceden en el tiempo, compartiendo un núcleo común pero divergiendo en aspectos significativos (Lakatos, 1983, pp. 65-6), parece que podemos concluir que la medicina tropical, en su conjunto, es el desarrollo de un mismo programa de investigación.

Este programa exige no sólo poder diferenciar el estudio de la microbiología de los estudios provenientes de la historia natural, "ser un naturalista antes que un bacteriólogo o un médico" (Manson, 1898, p. xvi); reclama una distinción entre el aclimatacionismo y la biogeografía, dado el rol causal secundario o indirecto del clima, "la fauna tropical ejerce mayor influencia que el clima per se"; y demanda, finalmente y de manera explícita, una respuesta a las "condiciones sociales y sanitarias de vida en los trópicos" asociadas a la propagación, a la persistencia y a la multiplicación de las enfermedades cosmopolitas en los trópicos.

\section{REFERENCIAS BIBLIOGRÁFICAS}

Arnold, D. 1996

Benchimol, Jaime 1999

Bourdieu, P. 2001

Bourdieu, P. 1982

Bowler, P.

$$
1998
$$

Brossollet, J.

$$
2000
$$

Bynum, W. and Overy, C. (eds.) 1998

Cook, G. 1995
Warm climates and Western medicine: the emergence of tropical medicine. Atlanta, Rodopi.

Dos micróbios aos mosquitos. Rio de Janeiro, Editora Fiocruz/UFRJ.

Science de la science et reflexivité. Paris, Raisons d'Agir.

Ce que parler veut dire. Paris, Fayard.

História Fontana de las ciencias ambientales. México, Fondo de Cultura Económica.

Pourquoi la peste? Le rat, la puce et le bubon. Paris, Gallimard.

The best in the mosquito: the correspondence of Ronald Ross and Patrick Manson. Atlanta, Rodopi.

Manson's Tropical Diseases. London, Saunders Company. 


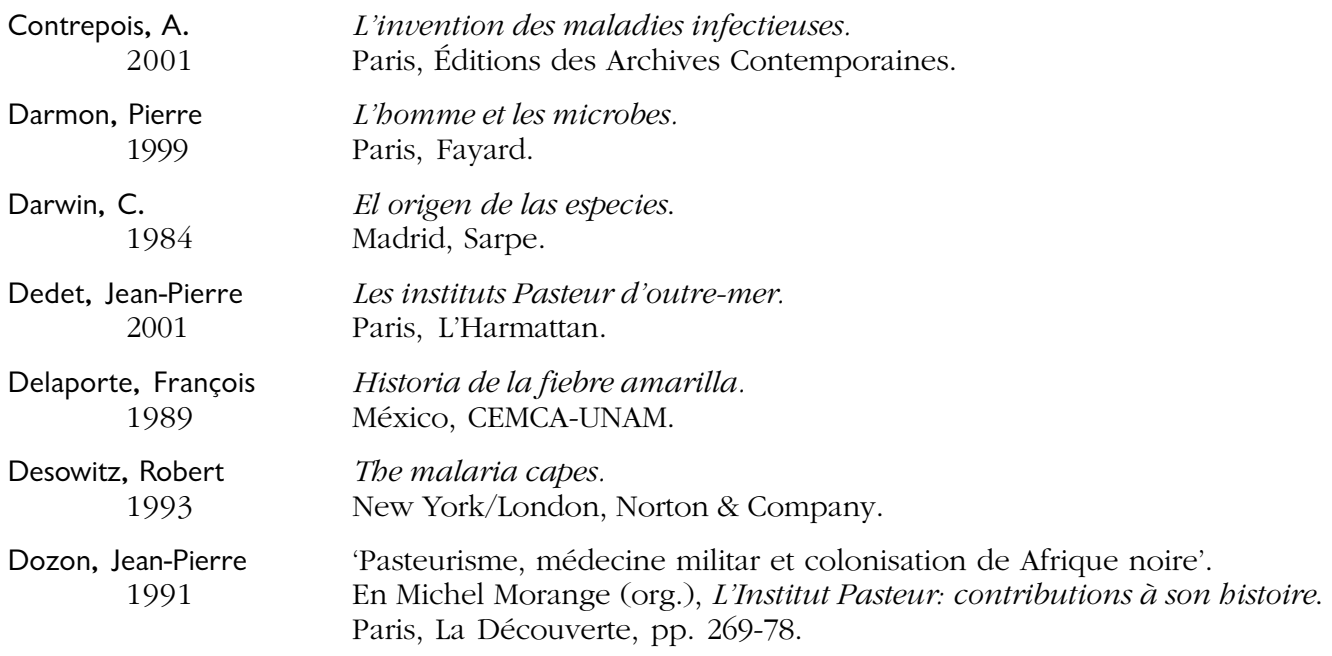

El origen de las especies. Madrid, Sarpe.

Les instituts Pasteur d'outre-mer Paris, L'Harmattan.

Historia de la fiebre amarilla. México, CEMCA-UNAM.

The malaria capes. New York/London, Norton \& Company.

'Pasteurisme, médecine militar et colonisation de Afrique noire'. En Michel Morange (org.), L'Institut Pasteur: contributions à son histoire. Paris, La Découverte, pp. 269-78.

Edler, F.

Edler, F. maio-ago 2000

Fantini, Bernardino 1999

Guillet, P. 2000

Hacking, I. 1985

Kuhn, T.

Lakatos, I.

Latour, B.

Latour, B. e Woolgar, S. 1997

Laveran, A. 1892

Limoge, C. 1976

Löwy, Ilana 2001

Löwy, llana 1991

Michel, Marc et Bado, J. P. 1991
A construção da medicina tropical no Brasil oitocentista: da climatologia à parasitologia médica. Tese de doutoramento, Rio de Janeiro.

'A Escola Tropicalista Baiana: um mito de origem da medicina tropical no Brasil.' En História, Ciências, Saúde - Manguinhos, Rio de Janeiro, vol. 9(2).

'La microbiologie médicale'.

En M. Grmek (éd.), Histoire de la pensée médicale en Occident. III. Paris, Seuil, pp. 115-46.

'La colonisation des zones tempérées par des vecteurs d'origine tropicale'. www.eid-med.org/Climato.

Revoluciones científicas.

México, Breviarios de Fondo de Cultura Económica.

La estructura de las revoluciones científicas.

México, Fondo de Cultura Económica.

La metodología de los programas de investigación científica.

Madrid, Aliansa Editorial.

Pasteur: guerre et paix des microbes.

Paris, La Découverte.

A vida de laboratório.

Rio de Janeiro, Relume Dumará.

Trypanosomes et tripanosomiases.

La selección natural. México, Siglo XXI

Virus, moustiques et modernité. Paris, Éditions des Archives Contemporaines.

'La mission del Institut Pasteur à Rio de Janeiro: 1901-1905'. En M. Morange (org.), L'Institut Pasteur: contributions à son histoire. Paris, La Découverte, pp. 279-95.

'Sur les traces du docteur Émile Marchoux: pionner de l'Institut Pasteur en Afrique noire'. En Michel Morange (org.), L'Institut Pasteur: contributions à son histoire. Paris, La Découverte, pp. 296-311. Paris, Archives de Médecine Experimentel. 
Manson, Patrik 1998

Manson, Patrik 1898

Moulin, A. M. 1999

Moulin, A. M. $1996 a$

Moulin, A. M. 1996b

Molina, G. 1999

Morange, $M$. 1991

Naraindas, $\mathrm{H}$. 1996

Nordenskiöld, E. 1949

Osborne, N. 1994

Peard, J. 1996

Power, Helen and Wilkinson, Lise 1998

Rehbock, Philip 1983

Rochard, J. 1886

Ross, $\mathrm{R}$. 1998

Sober, E.

Warrell, D. (ed.) 1998

Worboys, M. 1996
'Correspondence to Ross'. En W. Bynum e C. Overy (eds.), The best in the mosquito: the correspondence of Ronald Ross and Patrick Manson. Atlanta, Rodopi.

Tropical Diseases.

London, Cassell and Company.

'Les germes d'une nouvelle médecine'.

En Les sciences d'Europe s'imposent au monde.

Paris, Excelsior, pp. 72-81. Les Cahiers de Science et vie, no 50.

'Tropical without the tropics: the turning-point of Pastorian medicine in North Africa'. In David Arnold, Warm climates and Western medicine: the emergence of tropical medicine. Atlanta, Rodopi, pp. 160-80.

'De la médecine tropical à la santé au pluriel'. En Médecines et santé. Paris, Orston, pp. 7-23.

'Biogéographie'. En Dominique Locourt (org.), Dictionnaire d'histoire et philosophie des sciences. Paris, PUF.

L'Institut Pasteur: contributions à son histoire. Paris, La Découverte, pp. 240-42.

'Poisons, putrescence and weather: a genealogy of the medicine'. En Anne Moulin (ed.), Médecines et santé. Paris, Orston, pp. 31-50.

Evolución histórica de las ciencias biológicas.

Buenos Aires, Espasa-Calpe.

Nature, the exotic, and the science of French colonialism. Indiana, Indiana University Press.

"Tropical medicine in nineteenth-century Brazil: the case of the Escola Tropicalista Bahiana, 1860-1890". En A. David, Warm climates and Western medicine: the emergence of tropical medicine. Atlanta, Rodopi, pp. 108-30.

'The London and Liverpool Schools of tropical medecine, 1898-1998'.

En David Warrell (ed.), Tropical medicine: achievements and prospects. London, The Royal Society of Medicine Press, pp. 281-92.

The philosophical naturalists.

Madison, The University of Wisconsin Press.

'L'acclimatement'. En Revue des deux mondes. Paris, vol. 67, pp. 651-80.

'Correspondence to Manson'. En W. Bynum e C. Overy (eds.), The best in the mosquito: the correspondence of Ronald Ross and Patrick Manson. Atlanta, Rodopi.

Philosophy of biology.

Oxford, Oxford University Press.

Tropical medicine: achievements and prospects. London, The Royal Society of Medicine Press.

'Germs, malaria and the invention of Mansonian tropical medicine: from diseases in the tropics to tropical diseases. En A. David, Warm climates Western medicine: the emergence of tropical medicine. Atlanta, Rodopi, pp. 181-207.

Recebido para publicação em outubro de 2002. Aprovado para publicação em novembro de 2002. 